\title{
PANEL TESTS FOR THERMAL SPALLING OF FIRE-CLAY BRICKS USED AT HIGH TEMPERATURES
}

\author{
By R. A. Heindl and W. L. Pendergast
}

\section{ABSTRACT}

Fifty brands of fire-clay brick, of which 16 were of the super duty, 28 of the high heat duty, and 6 of the intermediate heat duty classes, were tested for resistance to spalling by the standard method of the American Society for Testing Materials. Variations from the standard panel of brick in stretcher construction were made by laying brick as headers only, and also in combinations of stretchers and headers. The relation of gas pressure in the conditioning, or preheating, furnace, within the range 0.2 to 0.6 inch of water, to the spalling of firebrick was also investigated. The stability of volume and change in absorption resulting from reheating new specimens at $1,600^{\circ} \mathrm{C}$ for 5 hours under conditions of controlled gas pressure were determined of all the brands of the super duty class of brick as well as of 10 brands of the high heat duty class, the latter being reheated at $1,400^{\circ} \mathrm{C}$ only. The relation between the spalling loss by gravity only and after scraping with a trowel was investigated, as was also the relation between the spalling loss and the number of joints in the brick panel.

\section{CONTENTS}

Page

I. Introduction

II. Materials _._.

III. Apparatus and methods of testing

1. ASTM panel furnaces _...

2. Types of panel construction

(a) Firebrick in stretcher construction

(b) Firebrick in header construction

(c) Firebrick in combination of header and stretcher construc-

(d) Construction of panels with firebrick as $4 \frac{1}{2}$-inch stretchers and as bonded headers

3. Spalling loss

4. Pressure and atmosphere within the furnace during preheating of the brick

5. Temperature and temperature measurements of brick panels ....

6. Linear change and volume stability

(a) Furnace pressure

(b) Furnace temperature

7. Pyrometric cone equivalent

8. Absorption and bulk density

IV. Results and discussion

1. Tests of the super duty class of fire-clay brick

(a) Spalling tests

(1) Effect of furnace pressure on spalling of firebrick $\mathrm{k}_{\ldots} \ldots 3$

(2) Uniformity of specimens

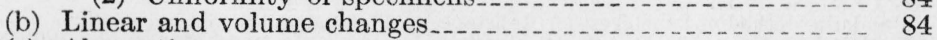

(c) Absorption 86

(d) Pyrometric cone equivalent

(e) Bulk density ........ 86 
IV. Results and discussion-Continued.

2. Tests of the high heat duty class of fire-clay brick ............ 86

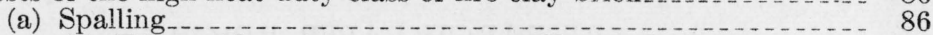

(1) Effect of furnace pressure on spalling of firebrick ...... 90

(2) Uniformity of specimens_... _...

(b) Pyrometric cone equivalent _....................... 91

(c) Linear, volume, and absorption changes caused by reheating_. 91

3. Panel spalling test of the intermediate heat duty class of fire-clay

brick ...

4. Comparison of header and $4 \frac{1}{2}$-inch stretcher construction

5. Comparison of bonded header and unbonded header construction.. V. Summary and conclusions

\section{INTRODUCTION}

The testing of fire-clay brick for resistance to thermal and structural spalling by the panel method was first described in $1926 .{ }^{1}$ Since then numerous improvements in both equipment and test procedure have led to closer control of furnace temperatures and pressures and made it possible to secure satisfactory agreement in results of tests in the same laboratory as well as in other laboratories. As more data became available additional information was published. ${ }^{2}$ However, it was not until July 1942 that the Refractories Fellowship at Mellon Institute issued a publication ${ }^{3}$ which outlined many details essential in constructing and operating the furnaces and test apparatus.

The panel test for resistance to thermal and structural spalling of refractory brick ${ }^{4}$ was adopted by the American Society for Testing Materials in 1936.

Federal Specification HH-B-671 for Fire-Clay Brick includes a water-dip quenching test of individual brick to give an index of spalling resistance, but the manufacturer usually relies on the ASTM panel test to give a measure of comparative spalling resistance. Since the results obtained by the two methods are not always in agreement, this may lead to confusion. Furthermore, the United States Navy makes use of apparatus for testing refractory brick, which is fundamentally similar to the ASTM standard. The desirability of having but one method of test is evident. The National Bureau of Standards, therefore, undertook an investigation of the spalling resistance of fireclay brick by the panel test method for the purpose of accumulating data for consideration in connection with the possible substitution of the panel test for the water-dip quenching test in the Federal specifications. The study was extended to include the effect of furnace pressure on resistance of brick to spalling and also the effect of certain deviations from the ASTM method with respect to construction of the test panels.

\section{MATERIALS}

Fifty brands of fire-clay bricks, of which 16 were of the super duty, 28 of the high heat duty, and 6 of the intermediate heat duty classes, were sampled, classified, and supplied by 19 manufacturers

1 S. M. Phelps, A Study of Tests for Refractories with Special Reference to Spalling Tests, Am. Refractories Inst. Tech. Paper No. 1. Mellon Institute of Industrial Research, Pittsburgh, Pa.

2 S. M. Phelps, S. M. Swain, and R. F. Ferguson, A service spalling test for refractories, J. Am. Ceram. Soc. 14 (5) 389 (1941).

Standard Method of Panel Test for Resistance to Thermal and Structural Spalling of Refractory Brick, ASTM Designation: C 38-42, Am. Soc. Testing Materials, Standards, pt. 2, Nonmetallic Materials, p. 250 (1942); Manual of AS'TM Standards on Refractory Materials, p. 23 (1943).

3 A recommended practice for use with the ASTM panel test for resistance to thermal and structural spalling, Refractories Fellowship, Mellon Institute, Pittsburgh, Pa. (July 1942) mimeographed.

See second reference given in footnote 2. 
representing all important centers of firebrick production. Second lots of each of four brands of the super duty class of brick and five of the high heat duty were received about 2 years after the first samples.

\section{APPARATUS AND METHODS OF TESTING}

\section{ASTM PANEL FURNACES}

The equipment for determining the resistance of firebrick to spalling has been described in detail elsewhere. ${ }^{5}$ Briefly, it consists of a preheating furnace, two sides of which are movable iron frames, each of which will accommodate a panel of 14 test specimens. A second furnace forms an integral part of the quenching equipment. A proportional mixer is used to supply the gas-air mixture for heating the furnaces. In the preheating furnace the panels of specimens are brought up to either $1,600^{\circ}$ or $1,650^{\circ} \mathrm{C}$ in about 7 hours and maintained there for 24 hours, after which they are allowed to cool with the furnace. The cool panel is then moved to a spalling furnace maintained at $1,400^{\circ} \mathrm{C}$ and there undergoes a 12-cycle treatment of heating for 10 minutes and then cooling for 10 minutes by a blast of air and water mist.

The apparatus used in this investigation was constructed essentially in accordance with drawings furnished by the Refractories Fellowship at Mellon Institute. Improvements have been added for automatically controlling the temperature in the furnaces and for safeguarding the apparatus against damage by possible explosiion in case of power failure. The hazard in lighting the preheating furnace with a gas pilot light, as suggested in the recommended practice, has been eliminated by the use of an electric resistor-coil heater placed close to the burner opening. This remains in the furnace until there is no liklihood of the flame being extinguished.

Also the cloth sleeve or flexible joint connecting the horizontal and vertical sections of the sheet-iron air ducts of the cooling vents were eliminated. The "velometer," a direct reading air-velocity meter, was used for determining the velocity of the air at the vents. It was found that the volume and distribution of the air as it was discharged varied a great deal with change in position of the moving vents. This was due to the unfolding and folding or wrinkling of the cloth in different positions. The flexible joint was eliminated by extending the elbow downward in the horizontal pipe so the air would be discharged into an enlarged pipe section formed as the frustum of a cone attached to the vertical pipe of the oscillating unit.

Final measurements with the velometer were made at 110 points equally distributed over the outlet of each vent. Adjustments were made of the louvers, spray nozzles, and damper until the required $1,400 \mathrm{ft}^{3}$ of air per minute were delivered as nearly uniformly as possible from the vent. The variation in velocity from the average was approximately \pm 5.0 percent.

\section{TYPES OF PANEL CONSTRUCTION}

Since industrial furnace linings are constructed with brick laid either or both as headers or stretchers, Heindl and Mong ${ }^{6}$ investigated

\footnotetext{
${ }^{5}$ See footnote 2 .

${ }^{6}$ R. A. Heindl and L. E. Mong, Young's modulus of elasticity, strength, and extensibility of refractories in tension, J. Research NBS 17, 463 (1936) RP923.
} 
the extensibilities of [ispecimens of firebrick in two directions and found they may be markedly different crosswise and lengthwise of the brick. Also, Heindl ${ }^{7}$ has shown that the extensibility is directly related to the resistance of refractory ware to heat shock. Based on this information, the test panels in this investigation were constructed in the following described varieties. In all types of construction the brick were laid so that the faces that would come in contact with the flame were flush.

\section{(a) FIREBRICK IN STRETCHER CONSTRUCTION}

The testing of the brick in the first phase of the investigation proceeded with all brick bedded in kaolin as stretchers and as specified in the "Standard method of panel test for resistance to thermal and structural spalling of refractory brick." 8

\section{(b) FIREBRICK IN HEADER CONSTRUCTION}

Each brick for the test was cut in half parallel to the $2 \frac{1}{2}$ by $4 \frac{1}{2}$-inch faces with a cut-off wheel. The halves were laid in the panel so that both of the original end faces were exposed as headers to the direct furnace heat. Fourteen halves cut from seven brick were used for the test and ordinarily two brands made up the panel. In a few panels the specimens were alternated instead of segregated.

\section{(c) FIREBRICK IN COMBINATION OF HEADER AND STRETCHER CONSTRUCTION}

The brick in these tests were laid in the panels so the first and sixth courses from the bottom were headers. The panels, each of 1 brand only, consisted of 8 brick in the header position and 10 in the stretcher.

(d) CONSTRUCTION OF PANELS WITH FIREBRICK AS 41/2-INCH STRETCHERS AND AS BONDED HEADERS

Since the tendency is for the spalling to begin along the edges of the brick, it should follow that either headers or one-half stretchers should have greater spalling losses than that of a full-sized stretcher. A number of tests were therefore made in which the bricks were cut in half parallel to the $2 \frac{1}{2}$ - by $4 \frac{11}{2}$-inch dimension and laid in the panel stretcherwise.

A number of tests were made of panels in which each of the individual specimens was made of two-header brick bonded with an airsetting refractory mortar. When laid in the panel the face of the brick specimen exposed to the flame was 9 inches long, but consisted of the finished or original two $2 \frac{1}{2}$ - by $4 \frac{1}{2}$-inch faces of the brick. The mortar joint was not disturbed until all regular tests were completed; then the joint was broken and the additional data desired were noted.

\section{SPALLING LOSS}

The loss due to spalling of the bricks was determined in accordance with the recommended method ${ }^{9}$ of scraping off the adhering kaolin bedding with a mason's trowel, which caused some of the spalls to drop off, but the face of the specimen that had been in contact with the

\footnotetext{
7 R. A. Heindl, A study of sagger clays and sagger bodies, J. Research NBS 15, 255 (1935).

8 See second reference given in footnote 2 .

- A recommended practice for use with the ASTM!panel test for resistance to thermal and structural spalling, 42, Refractories Fellowship, Mellon Institute (July 1942) mimeographed.
} 
flame was not scraped. However, since there is a personal factor involved in that method, the loss which had occurred before scraping was also recorded. The results tabulated in succeeding tables are the total losses. These represent those obtained by gravity plus those that drop off when the kaolin is removed by scraping.

\section{PRESSURE AND ATMOSPHERE WITHIN THE FURNACE DURING PREHEATING OF THE BRICK}

The pressure in the furnace was easily regulated at any value within the range 0.0 to 0.6 inch of water to 0.05 inch by adjusting the damper in the flue. The pressure was indicated by the pointer of a dial-type draft gage having a range of 0 to 1 inch and graduated in 0.05 inch. To determine if there was any relation between the pressure in the furnace during the 24-hour preheating period of the bricks and their resistance to spalling, numerous tests were made of bricks, different lots of which had been preheated at different furnace pressures. Panels of all brands of firebrick were tested after having been preheated with a pressure in the furnace of 0.4 inch of water and, in addition, other panels of some brands were tested also after having been preheated with pressures of 0.2 and 0.6 inch of water.

When a furnace pressure of 0.6 inch of water was used, the excess air approached the upper limit of the 10 to 20 -percent range and the $\mathrm{CO}_{2}$ content was about 11 percent. With a furnace pressure of 0.2 inch the excess air was closer to the lower end of the 10- to 20-percent range, which resulted in a $\mathrm{CO}_{2}$ content of approximately 12 percent. These relations were observed when the $600-\mathrm{B}$ tu gas available at the National Bureau of Standards was used and the directions given in the recommended practice followed. ${ }^{10}$

\section{TEMPERATURE AND TEMPERATURE MEASUREMENTS OF BRICK PANELS}

Firebrick of the super duty class were preheated at $1,650^{\circ} \mathrm{C}$, those of the high heat duty class at $1,600^{\circ} \mathrm{C}$, and those of the intermediate heat duty class at $1,500^{\circ} \mathrm{C}$ and in some cases at $1,600^{\circ} \mathrm{C}$, for 24 -hour periods. The spalling test was made from $1,400^{\circ} \mathrm{C}$ for all three classes of brick.

The temperature of the furnace during preheating was measured by means of an optical pyrometer sighted on the hot face of the brick and at approximately the center of either one of the two panels. A recording type of radiation pyrometer sighted on the same spot automatically maintained the temperature throughout the 24-hour period of preheating. A thermocouple was placed against the back face of the panel at a point approximately opposite that on the hot face on which the optical pyrometer was sighted.

A special study of temperature distribution was made on one brand of firebrick. Three thermocouples were used during each of three tests at different furnace pressures. The first of these couples was embedded in the brick $1 \frac{1}{2}$ inches and the second 3 inches from the hot face; the third couple was $4 \frac{1}{2}$ inches from the hot face in contact with the back face of the specimen. In figure 1 is shown a portion of the

\footnotetext{
${ }^{10}$ A recommended practice for use with the ASTM. panel test for resistance to thermal and structural spalling, Refractories Fellowship, Mellon Institute, p. 12 (July 1942) mimeographed. The Btu heating value of the natural gas at Mellon Institute is about 1,130 .
} 
time-temperature relation during a 31-hour preheating of a panel of brick at a maximum temperature of $1,600^{\circ} \mathrm{C}$, with a pressure in the furnace chamber equivalent to 0.4 inch of water. The temperature of $1,600^{\circ} \mathrm{C}$ on the furnace wall or test brick panel was reached in 7 hours. Temperature equilibrium was not indicated by the three thermocouples until 7 to 10 hours later. These curves could be considered representative for all tests made at this furnace pressure, but would be different for the same brand preheated at a higher or at a lower pressure in the furnace chamber. For example, when a gas pressure of 0.6 inch was maintained in the furnace chamber, the temperatures $1 \frac{1}{2}$ and 3 inches back from the hot face were about $100^{\circ} \mathrm{C}$ higher than noted when the pressure in the furnace was 0.4 inch.

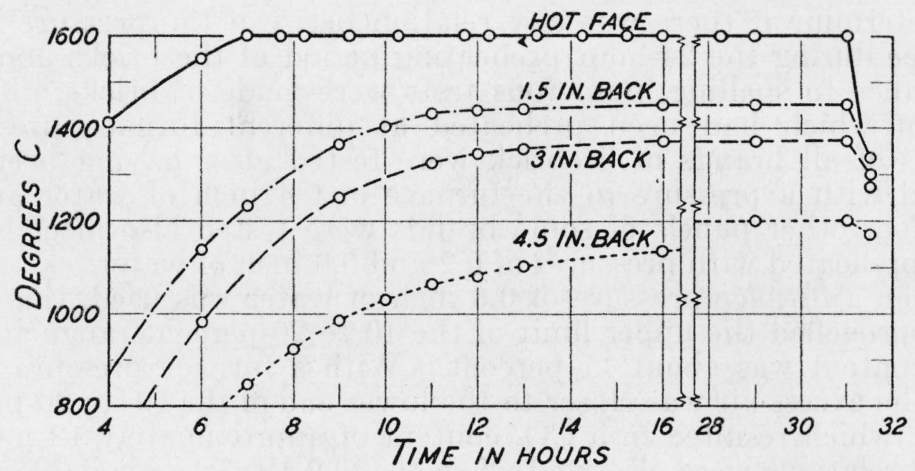

FIGURE 1.-Time-temperature relation during the 31-hour preheating period of a panel of firebrick at a maximum temperature of $1,600^{\circ} C$ with a gas pressure in the furnace chamber of 0.4 inch of water.

Temperatures were taken at four separate points.

The heat distribution over the face of the panel was determined approximately by placing standard pyrometric cones in recesses prepared in two panels for preheating at $1,600^{\circ} \mathrm{C}$. In one panel they were in the following positions: lower left, center, and upper right; and in the other, upper left, center, and lower right. After having been preheated, cone 30 was about three-quarters down in the center of either panel. In the lower-left position, which was also nearest the burner, cone 29 was down. The lower-right corner was the hottest, and cone 30 in this position was flat, but cone 31 was still upright. There was very little difference in the condition of the cones in the upper-right and upper-left corners; in each instance cone 30 was down. It was concluded that the temperature distribution in the furnace was reasonably good.

The thermocouple for measuring the temperature in the spalling furnace was about $9 \frac{1}{2}$ inches from the face of the panel and 12 inches from the bottom of the furnace, 9 inches from the inside back wall and 7 inches from the side. It was located behind the silicon carbide checkerbrick.

The curves in figure 2 indicate the time-millivolt (time-temperature) relation during the spalling test of one of three panels of firebrick in which this relation was determined. Since the data were approximately similar in those three cases, it may be assumed that they are 
representative of all tests. Four thermocouples were distributed as follows: The first in the furnace chamber, as noted in the preceding paragraph; the second on the hot face of the panel; and the third and fourth embedded in the brick $1 \frac{1}{2}$ and 3 inches back from the hot face, respectively. These curves show that the temperatures in the furnace and $3 \frac{1}{2}$ inches from the hot face remained fairly constant, except that in the latter a gradual drop in temperature of about 100 degrees occurred during the test. The couple on the face illustrated that the cooling at that point was almost instantaneous with a drop in temperature of about 1,300 degrees. The heating at this same point was almost equally as rapid up to about $1,200^{\circ} \mathrm{C}$. The temperature indicated by the thermocouple $1 \frac{1}{2}$ inches from the hot face fluctuated about 100 degrees during each heating and cooling cycle. Although

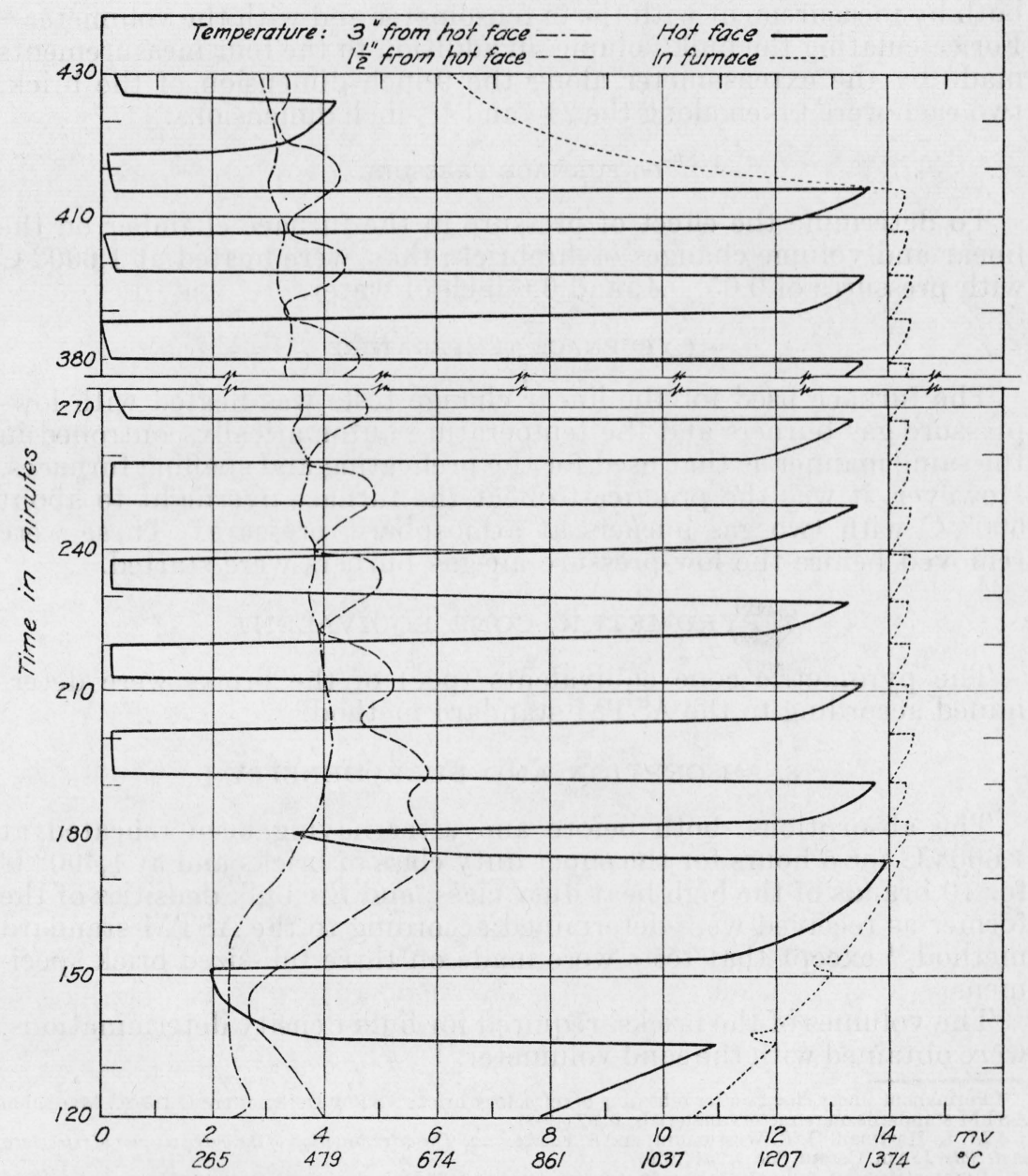

FIGURE 2.-Reproduction of lines recorded automatically by instruments to indicate temperatures (in millivolts) at four different points during certain stages in the progress of the spalling test.

$623634-45-6$ 
it registered approximately $665^{\circ} \mathrm{C}$ at the beginning of the test, this thermocouple indicated a gradually decreasing temperature until at the last cycle it registered only about $500^{\circ} \mathrm{C}$ maximum.

\section{LINEAR CHANGE AND VOLUME STABILITY}

The linear changes of new specimens of firebricks of both the super duty and high heat duty classes due to reheating were determined according to the ASTM standard method. ${ }^{11}$. Measurements were made in two ways, namely, with the extensometer equipped with an Ames dial graduated in 1/1,000 inch and a hook rule graduated in $1 / 64$ inch. With the former, four readings were taken and with the latter, two, for each specimen.

The change in volume was determined on the same brick specimens, both by measurement with the extensometer and with the volumeter. ${ }^{12}$ For calculating the bulk volume, in addition to the four measurements made by the extensometer along the 9 -inch dimension of the brick, two each were taken along the $21 / 2$ - and $4 \frac{1}{2}$-inch dimensions.

\section{(a) FURNACE PRESSURE}

To determine the effect of pressure in the furnace chamber on the linear and volume changes of firebrick, they were heated at $1,600^{\circ} \mathrm{C}$ with pressures of $0.05,0.4$, and 0.6 inch of water.

\section{(b) FURNACE TEMPERATURE}

The furnace used for the linear change tests was heated with lowpressure gas burners and the temperature automatically controlled in the same manner as that used for the preheating and spalling furnaces. However, it was the practice to heat the furnace overnight to about $600^{\circ} \mathrm{C}$ with two gas burners at atmospheric pressure. These were removed before the low-pressure air-gas burners were started.

\section{PYROMETRIC CONE EQUIVALENT}

The pyrometric cone equivalents (pce) of the bricks were determined according to the ASTM standard method. ${ }^{13}$

\section{ABSORPTION AND BULK DENSITY}

The absorptions, both before and after having been reheated at $1,600^{\circ} \mathrm{C}$ for 5 hours for the super duty class of bricks and at $1,400^{\circ} \mathrm{C}$ for 10 brands of the high heat duty class, and the bulk densities of the former as received were determined according to the ASTM standard method, ${ }^{14}$ except that tests were made on three full-sized brick specimens.

The volumes of the bricks, required for bulk density determinations, were obtained with the sand volumeter. ${ }^{15}$

11 Permanent linear change after reheating of refractory brick, ASTM. Designation: C 113-36, Manual of A STM standards on refractory materials, p. 62 (1943).

${ }_{12}$ M. L. Hartman, O. B. Westmount, and S. F. Morgan, The determination of the bulk volumes of refractory materials, J. Am. Ceram. Soc. 9, 298 (1926).

13 Pyrometric cone equivalents of refractory materials, ASTM designation: C 24-42, Manual of ASTM standards on refractory materials, p. 58 (1943).

14 Apparent porosity, water absorption, apparent specific gravity, and bulk density of burned refractory products, C 20-41, Manual of ASTM standards on refractory materials, p. 70 (1943).

is See footnote 12 . 

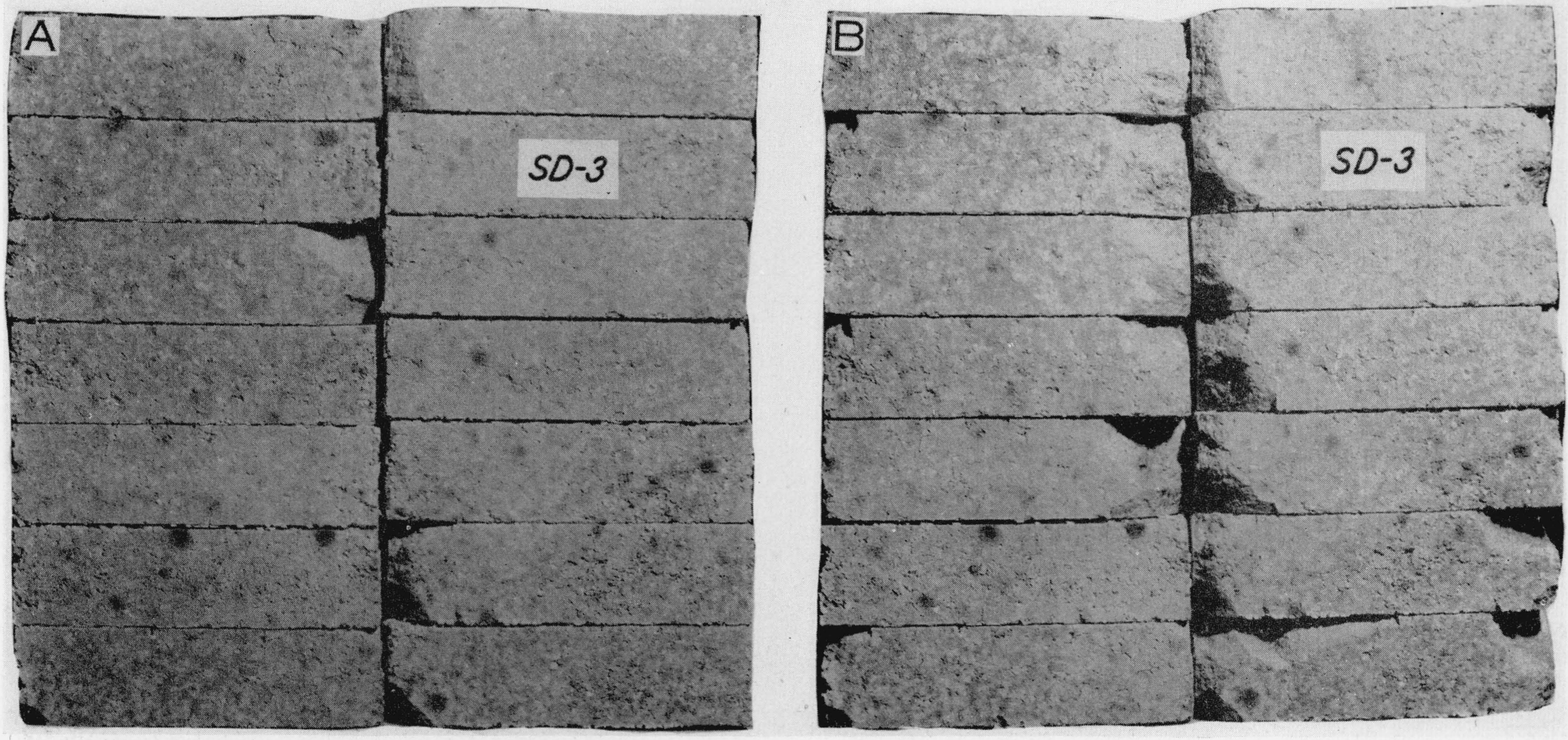

FIGURE 3.-Brand SD-3 after having been tested and removed from a panel of all stretcher construction. 4 , the specimens have not been scraped for removal of kaolin bedding; $B$, the same specimens after scraping. 

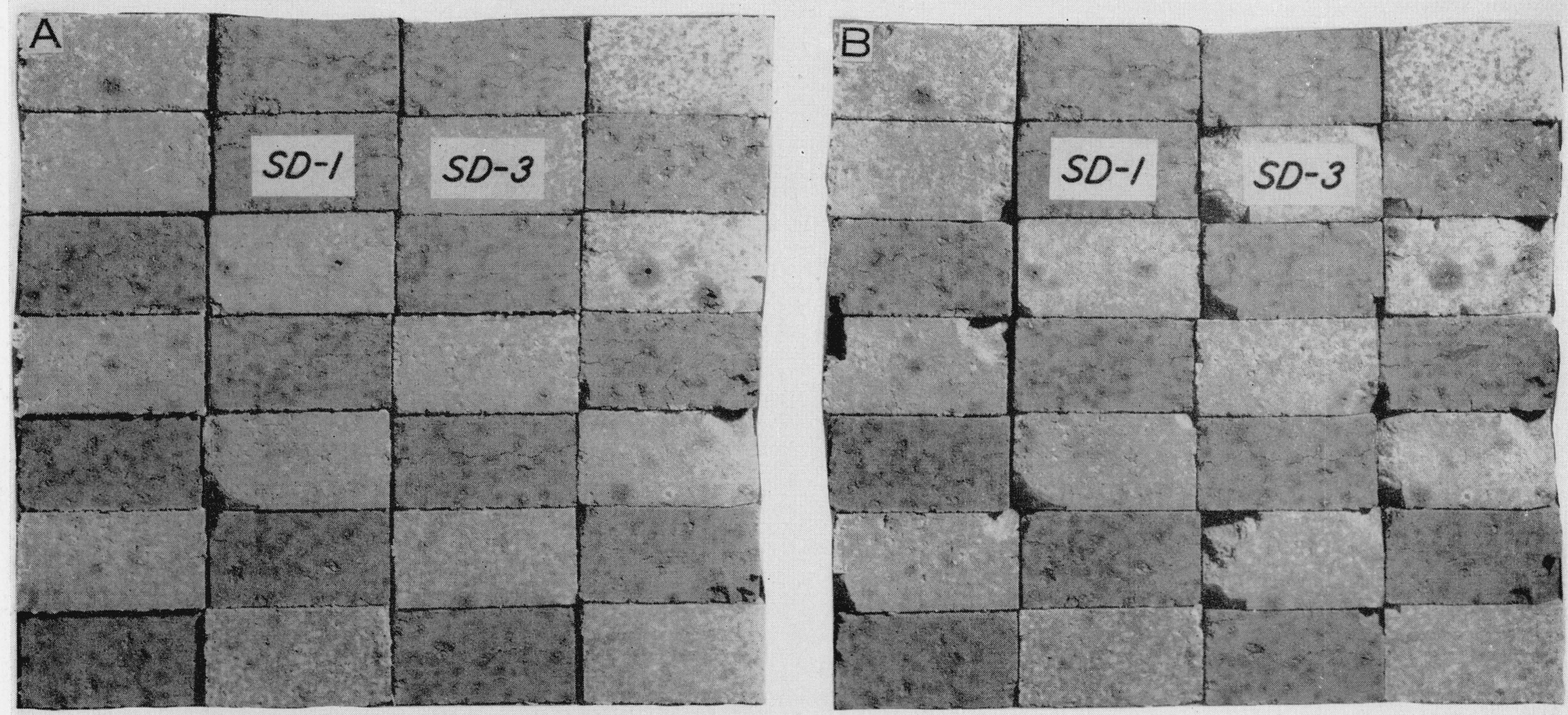

FIGURE 4.-Brand SD-1 (dark specimens) and brand SD-3 after having been tested and removed from a panel of all header construction. $A$, the specimens have not been scraped; $B$, the same specimens after scraping. 


\section{RESULTS AND DISCUSSION}

\section{TESTS OF THE SUPER DUTY CLASS OF FIRE-CLAY BRICK}

\section{(a) SPALLING TESTS}

The results of all spalling tests of the super duty fire-clay bricks are given in table 1 . The dates of receipt of the samples are included to identify cases where a second lot was received.

TABLE 1.-Spalling losses of the super duty class of fire-clay bricks in panel ${ }^{1}$ tests

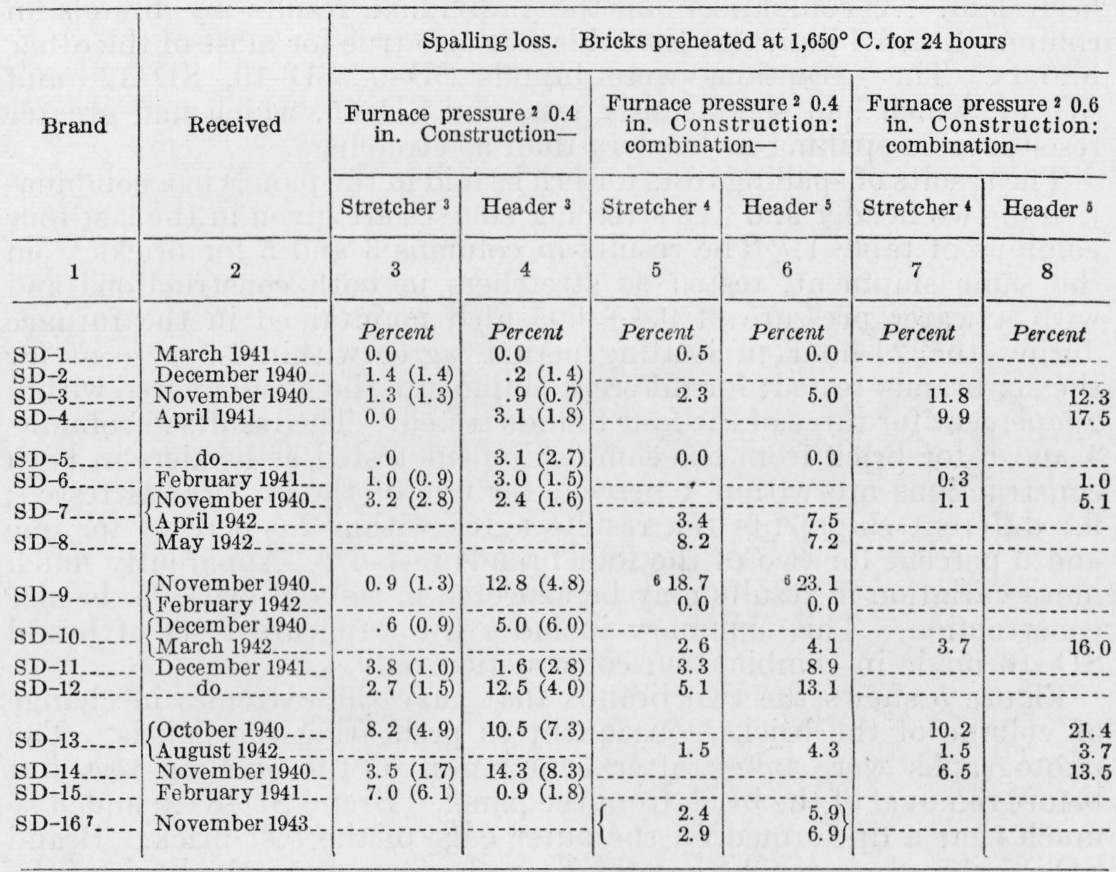

1 Panels consisted of all stretcher courses (column 3), all header courses (column 4), or a combination of 5 stretcher and 2 header courses (columns 5 to 8). In the last-named construction, the header courses were numbers 1 and 6 , counting from the bottom, except brand SD-9 (second shipment), in which case the header courses were numbers 2 and 6.

2 Furnace pressure given in inch of water. The pressure ranges were $0.4 \mathrm{in} . \pm 0.05 \mathrm{in}$. and $0.55 \mathrm{in}$. to $0.6 \mathrm{in}$., respectively.

${ }_{3}$ A verage of 14 specimens from 1 panel (exception SD-11 stretcher construction, 12 specimens only). Standard deviation for the individual brick is given in parentheses following the percentage spalling loss The deviations for brands SD-8 and SD-16 for the combination panels (columns 5 and 6) are: Stretcher 3.1 and 3.8 , header 3.5 and 10.6 , respectively.

${ }_{4}^{4}$ A verage of 10 specimens.

s A verage of 8 specimens (exception SD-13, column 6, average 6 specimens).

6 Values given only to illustrate effect on spalling when flame penetrated to back of specimens, and are not comparable with the other results.

72 panels of this brand were tested at the same time.

The losses sustained in the spalling test when the entire panel of 14 brick was laid as stretchers, and the pressure in the furnace was maintained at 0.4 inch of water, are given in column 3 . Figure 3 shows two views of brand SD-3 representative of this type of construction. $A$ shows the brick after completion of the test but before removal of the spalled pieces; and $B$, the same brick after the kaolin bedding and adhering spalls had been removed by scraping. The 1.3 percent loss was low and compared favorably with the loss shown by 
most of the other brands. Only two brands, SD-13 and SD-15, had outstandingly high spalling losses.

The losses sustained in the spalling test when all the bricks were laid in the panels as headers and the pressure in the furnace was 0.4 inch of water are given in column 4 . Figure $4, A$, shows brands SD-1 and SD-3 after having been tested but not scraped to remove adhering kaolin, and $B$, the same brick after completion of the scraping operation. Brand SD-1 had no loss, and the loss of 0.9 percent sustained by SD-3 was very low. Both brands resisted spalling exceptionally well regardless of the direction in which the brick had been laid. A comparison of the individual results by brands in columns 3 and 4 indicates that this was also true for most of the other brands. The exceptions were brands SD-9, SD-10, SD-12, and SD-14, which had significantly less, and SD-15, which had greater resistance to spalling as headers than as stretchers.

The results of spalling tests for bricks laid in the panels in a combination of two header and five stretcher courses are given in the last four columns of table 1 . The results in columns 3 and 5 for bricks from the same shipment, tested as stretchers in both constructions and with a water pressure of $0.4 \pm 0.05$ inch maintained in the furnace during the 24-hour preheating period, agree within 2.5 percent for the six brands tested; for different shipments the results agree within 2.5 percent for three of the four brands tested. The results in columns 4 and 6 for brick from the same shipment tested as headers in both constructions are within 4 percent for five of the six brands tested; for different shipments the results agree within 2.5 percent for one and 6 percent for two of the four brands tested. ${ }^{16}$ Apparently much more variation in results may be expected in tests of bricks in header construction. This summary includes the duplicate tests of brand SD-16 made in combination construction only.

Figure 5 shows the two brands that gave the extremes in change of volume of the bricks consequent to preheating the panels. The photographs were taken after completion of the spalling test but before removal of the brick from the panel. Brand SD-8 expanded so much that a lip formed on the outer edge of the test brick. Brand SD-15 shrank so much that the flame had access to the back of the panel, as indicated by a thermocouple temperature of $1,470^{\circ} \mathrm{C}$. Since the range in the temperature at that location was from about $1,135^{\circ}$ to $1,300^{\circ} \mathrm{C}$ when other brands were tested, it was apparent that the back face of the panel was approximately 200 degrees higher than would be considered normal. The temperature of $1,470^{\circ} \mathrm{C}$ on the back face of the brick undoubtedly was partially the cause of the low resistance to spalling of brand SD-15. When SD-15 and SD-5 were laid as headers and staggered in the same panel so that SD-15 could not shrink as a unit and the maximum temperature on the back face of the brick was $1,255^{\circ} \mathrm{C}$, the spalling loss for SD-15, header construction, was 0.9 percent compared with 7.0 percent for all-stretcher construction. The detrimental effect of high temperature on the back face of the brick panel during preheating is also illustrated by SD-9, columns 5 and 6 . Although the brick specimens did not shrink, apparently they had not been locked securely into position in the steel framework. During preheating the brick tilted

\footnotetext{
${ }_{16}$ The quality of the second shipment of brand SD-13 was much higher than that of the first, as indicated by the test results. Also, a difference in structure of the brick in the two shipments was indicated by the spalled surfaces.
} 

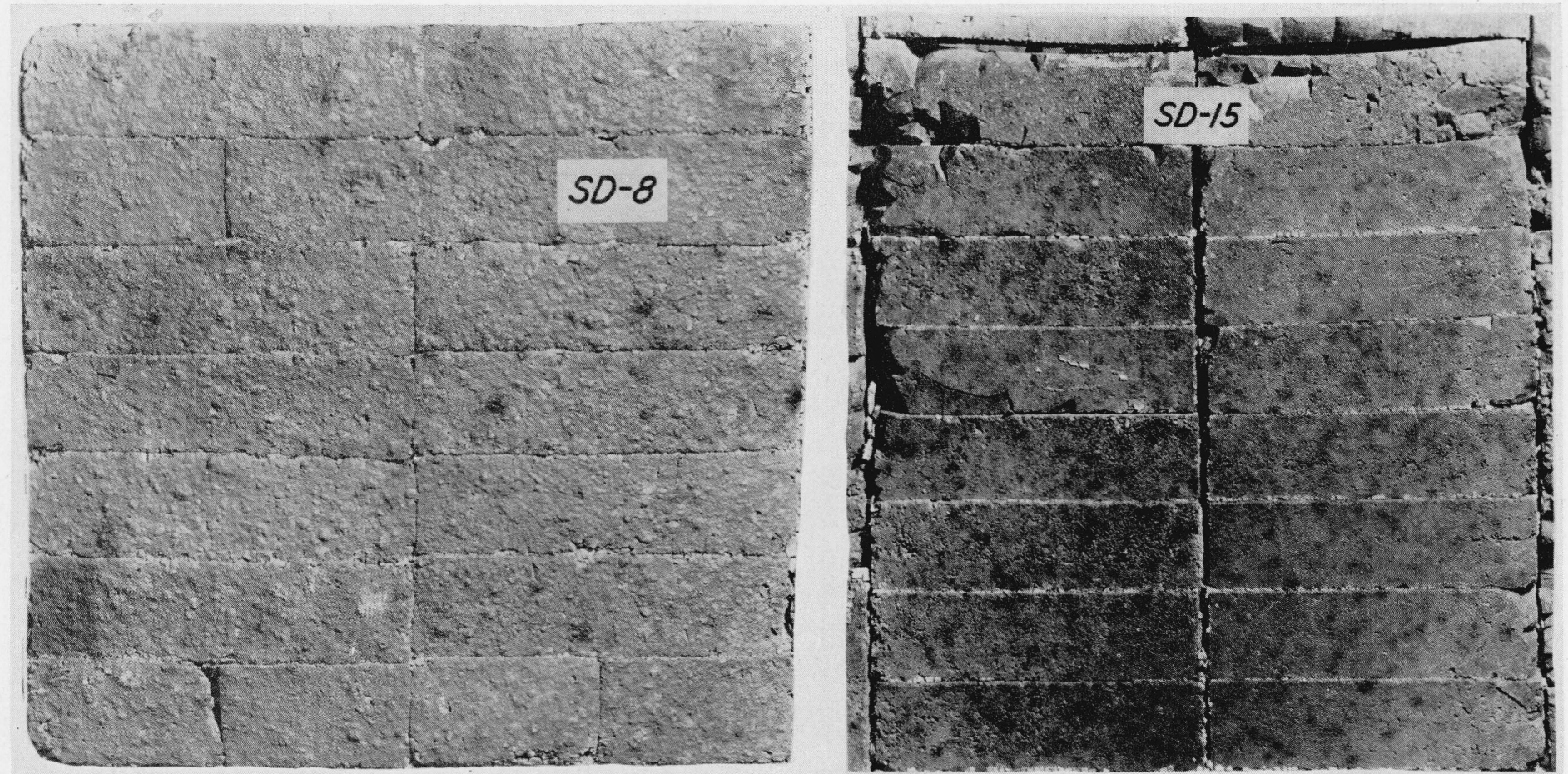

FIGURE 5.-Extremes in expansion and contraction illustrated by super duty brands SD-8 and SD-15, respectively.

The testing had been completed, but the specimens had not been removed from the panels. The photographs are not the same scale, since two dummy brick remain with brand SD-15. 

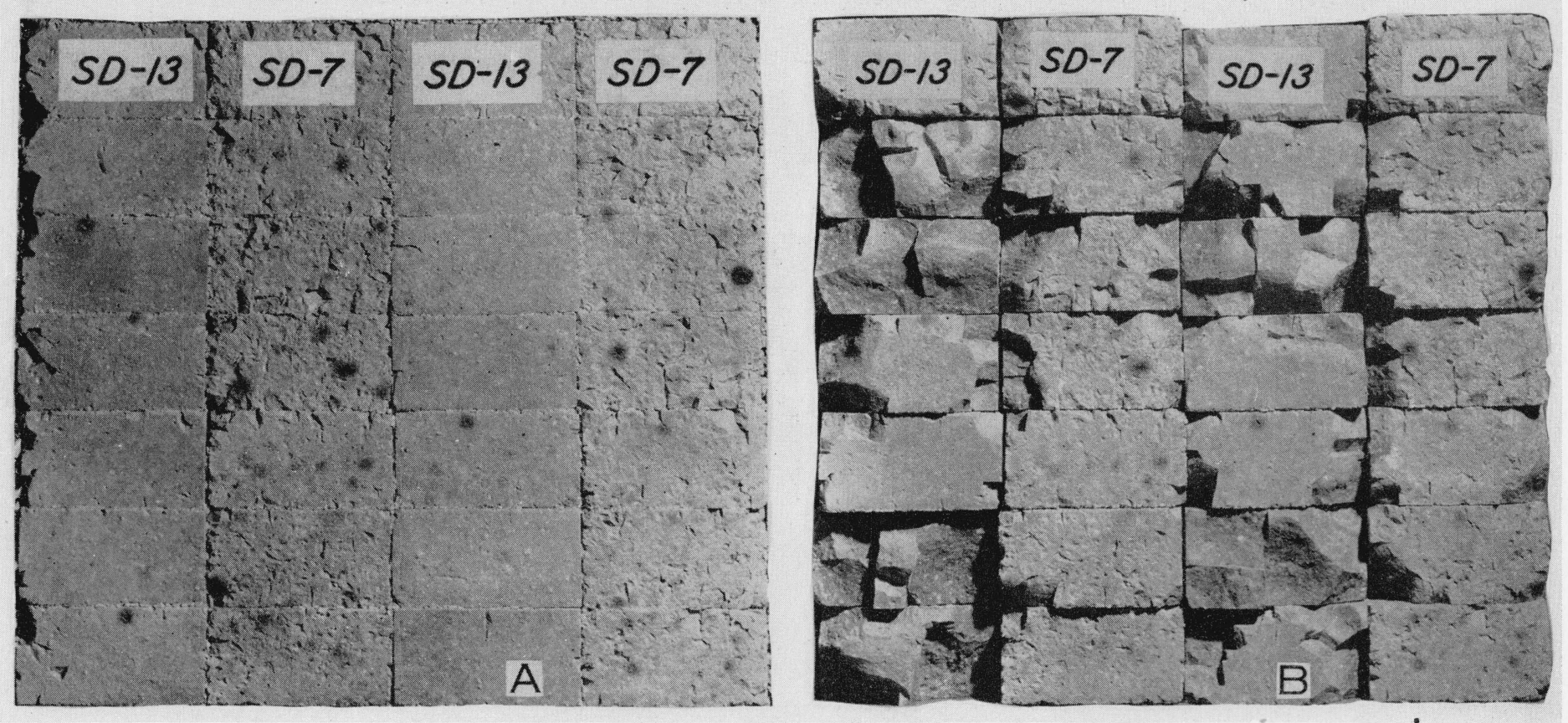

FigURE 6.-The two general types of spalling encountered in the super duty class of firebrick.

$A$, the specimens after completion of the spalling test; $B$, the specimens have been removed and scraped for removal of kaolin bedding. The spalled pieces of brand SD-7 were small and angular and by comparison those for SD-13 were large and conchoidal. 


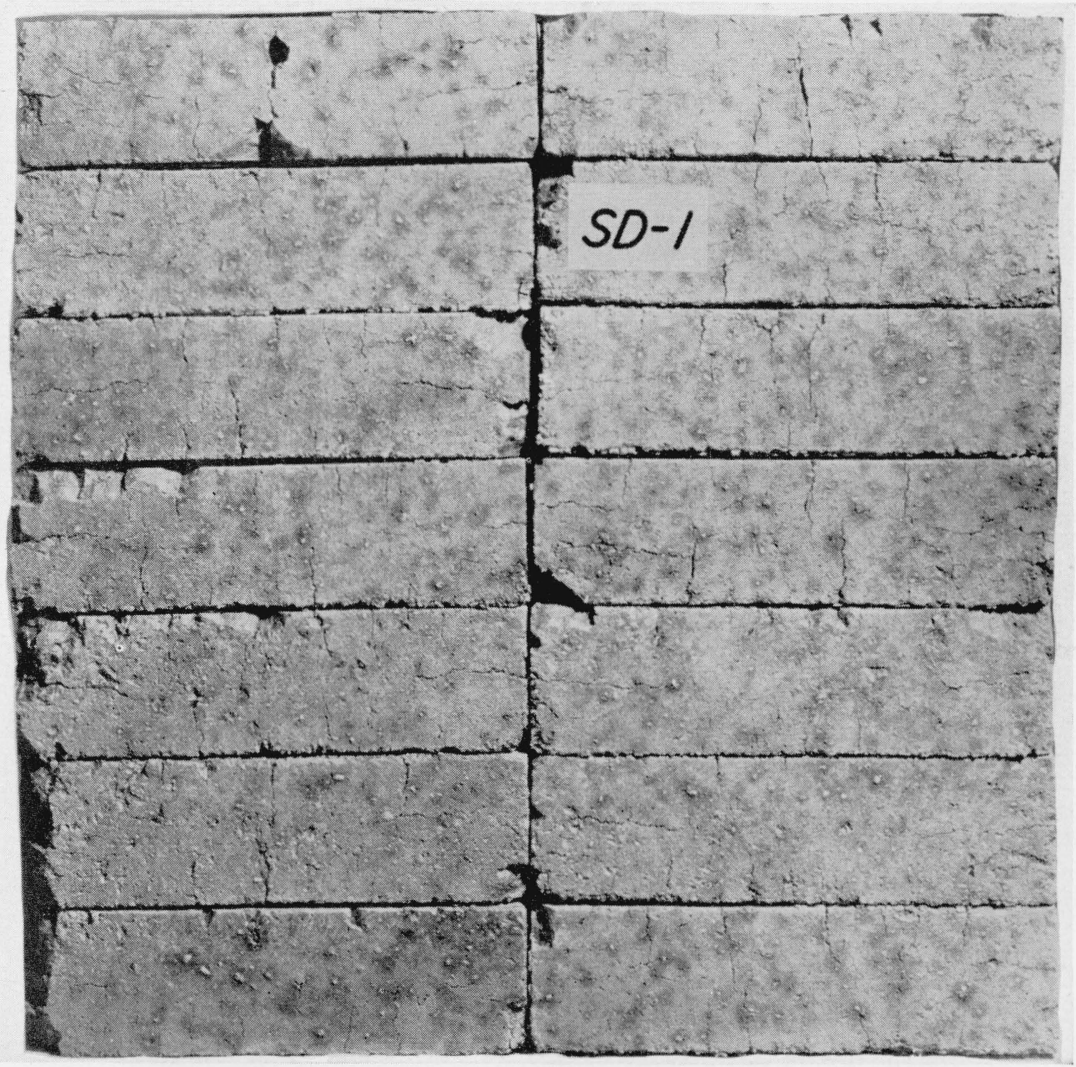

FIGURE 7.-Brand SD-1 after completion of the spalling test and scraping of the kaolin from the specimens.

The numerous visible cracks in the untested specimens apparently did not induce spalling. 

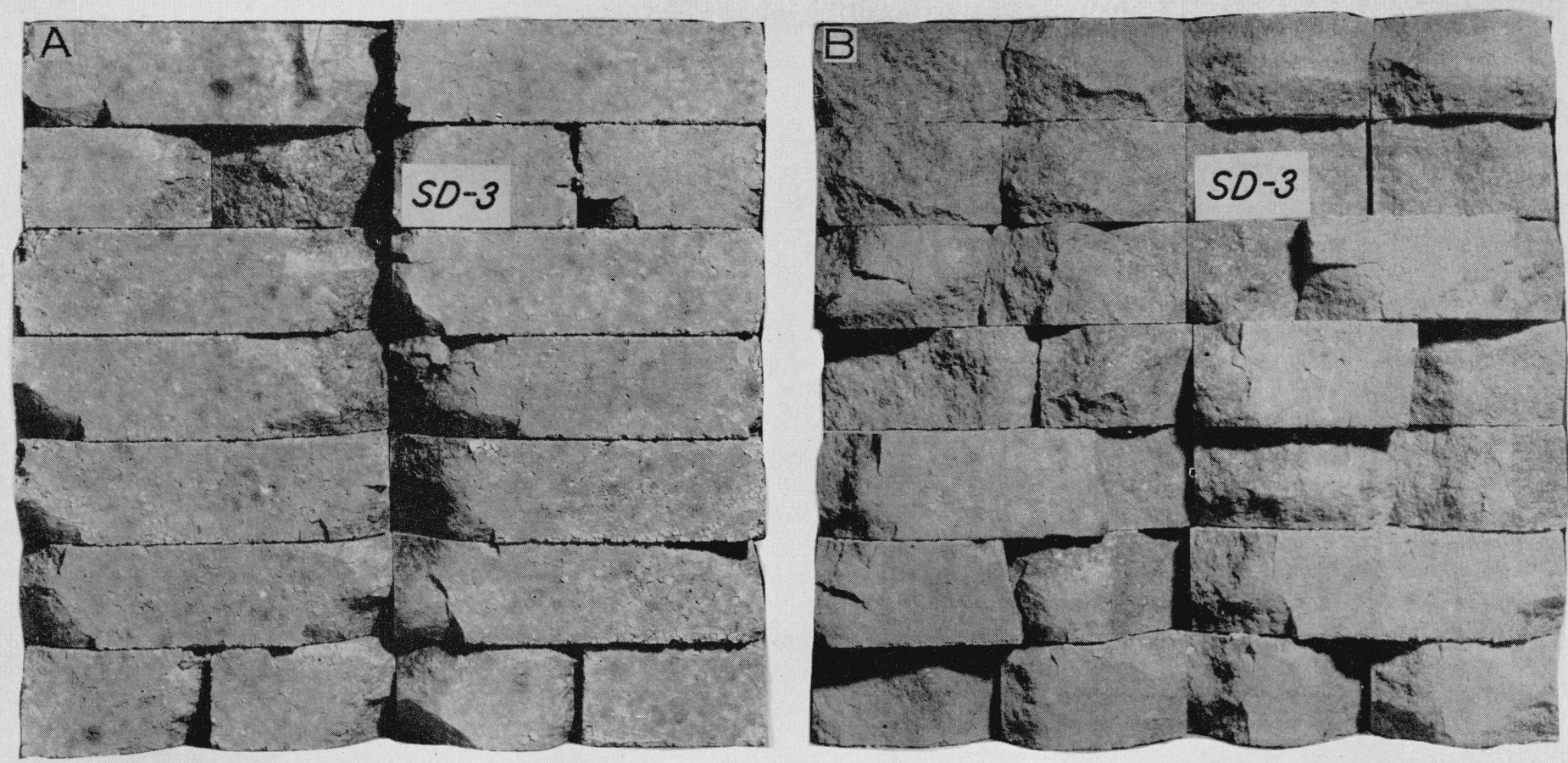

FIGURE 9.-Brand SD-3 after completion of tests with different furnace pressures.

The panel construction was a combination of five stretcher and two header courses. $A$, the specimens had been preheated with a pressure in the furnace chamber of 0.4 inch of water; $B$, with a pressure of about 0.6 inch. 
forward, permitting the flame to heat the rear of the panel so that here also a temperature of $1,470^{\circ} \mathrm{C}$ was indicated.

Two panels of brick SD-16 were simultaneously preheated and then tested for resistance to spalling. Since the results are in good agreement, reproducible conditions may be assumed for the two panels throughout the tests.

Two general types of spalling encountered in these tests are illustrated in figure 6 for brands SD-7 and SD-13, header construction. In the former the tendency was for the spalled pieces to be rather small and angular, whereas in the latter they were large and with conchoidal fracture. Figure $6, B$, shows the panel after the thermal shock treatment, and $A$, the specimens removed from the panel and the loose pieces dislodged. The brands having the greater losses usually have the conchoidal type of failure.

The specimens of brand SD-1 were of particular interest in that they had numerous small cracks along the edges which had developed during manufacture. These cracks, shown in figure 7 , became accentuated during the progress of the test and led to the erroneous assumption that the spalling resistance would be low.

(1) Effect of furnace pressure on spalling of firebrick.-The higher of the two pressures, namely, 0.4 and 0.6 inch, maintained in the furnace during the preheating period at $1,650^{\circ} \mathrm{C}$. did not affect detrimentally all of the eight brands so tested. For three brands, in which all conditions were identical except furnace pressure, the spalling increased with increase in furnace pressure for two brands and remained about unchanged for the third. Figure $8, S D$, illustrates that

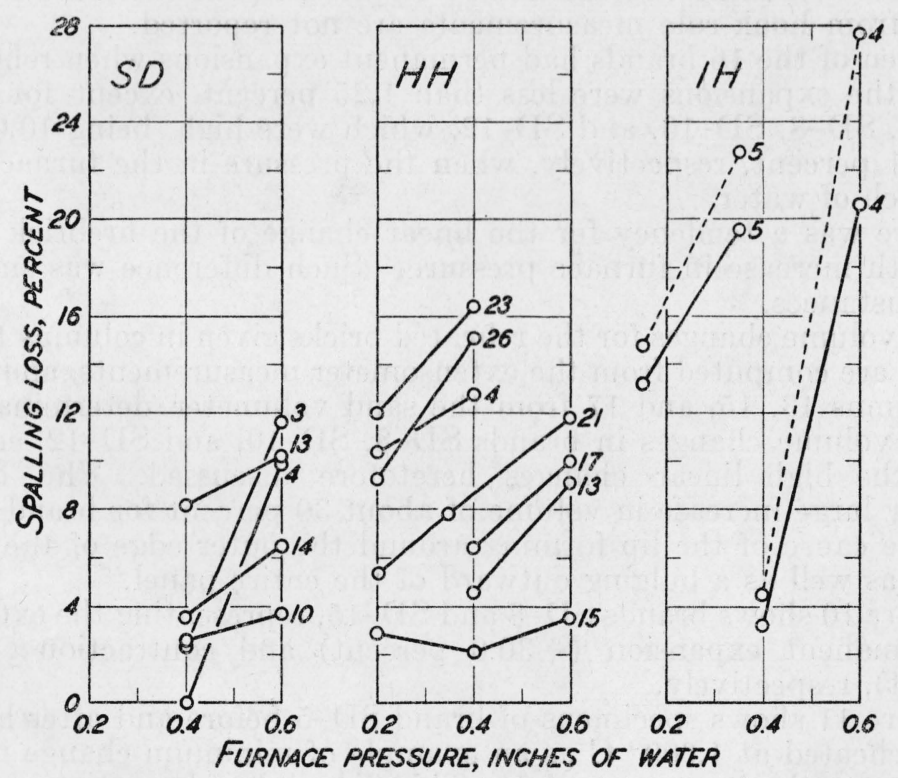

FIGURE 8.-Increased spalling accompanied increased pressure of the atmosphere in the furnace chamber.

$S D$ refers; to five brands of super?duty brick; $H H$ to seven of high heat brick; and $I H$ to two of the intermediate heat brick. Plotted points conrected with solid lines represent losses for stretcher construction and those with dashes, header construction. Although there were exceptions and all the results are not shown, the majority of the brands_were affected detrimentally by increased gas pressure during the preheating. 
relation for those brands and also for three others, stretcher construction only, in which the conditions, although not identical, were considered sufficiently similar to permit comparison. Figure 9 shows brand SD-3 in the combination stretcher and header type of panel construction after the losses due to spalling had been determined. Both panels of firebrick had been treated identically, except that panel $A$ was subjected to a pressure within the furnace of 0.4 inch and panel $B$ to a pressure of 0.6 inch during the preheating period at $1,650^{\circ} \mathrm{C}$.

(2) Uniformity of specimens.-The standard deviations ${ }^{17}$ of the spalling losses by the individual brick in all stretcher construction, as well as in all header construction for the brands that showed losses, reported in table 1 , columns 3 and 4 , give an indication of the uniformity of the firebrick in the samples.

\section{(b) LINEAR AND VOLUME CHANGES}

The linear changes caused by reheating the superduty class of bricks at $1,600^{\circ} \mathrm{C}$. for 5 hours, during which the pressure in the furnace was maintalned at $0.05,0.4$, or 0.6 inch of water, are given in table 2 , columns 9 to 11 , inclusive.

Although there are a few exceptions, the results indicate that it made little difference in the measured linear change whether the hook rule or the extensometer was used. This is of interest because the hook-rule measurements necessarily were taken around the outer edges of the specimens, whereas those taken with the extensometer represented points away from the edges. Because the differences in results between the two methods were insignificant the results computed from hook-rule measurements are not reported.

Eleven of the 16 brands had permanent expansions when reheated. All of the expansions were less than 1.25 percent, except for three brands, SD-8, SD-10, and SD-12, which were high, being 10.0, 4.5, and 5.1 percent, respectively, when the pressure in the furnace was 0.05 inch of water.

There was a tendency for the linear change of the firebrick to be less with increase in furnace pressure. Such difference was small in most instances.

The volume changes for the reheated bricks given in columns 12,14 , and 16 are computed from the extensometer measurements, and those in columns 13,15 , and 17 from the sand volumeter determinations.

The volume changes in brands SD-8, SD-10, and SD-12 emphasized the high linear changes heretofore discussed. The exceptionally large increase in volume of about 30 percent for brand SD-8 was the cause of the lip forming around the outer edge of the brick panel, as well as a bulging outward of the entire panel.

Figure 10 shows brands SD-8 and SD-15, representing the extremes in permanent expansion $(+30.0$ percent) and contraction $(-6.7$ percent), respectively.

Figure 11 shows specimens of brand SD-5 before and after having been reheated at $1,600^{\circ} \mathrm{C}$ as an example of minimum change in volume due to the heat treatment. This figure also shows specimens of $\mathrm{SD}-12$, the reheated specimen illistrating constriction near the middle

${ }_{17}$ Manual for interpretation of reíractory test data, ASTM Standards on Refractory Materials (Feb. 1935). 

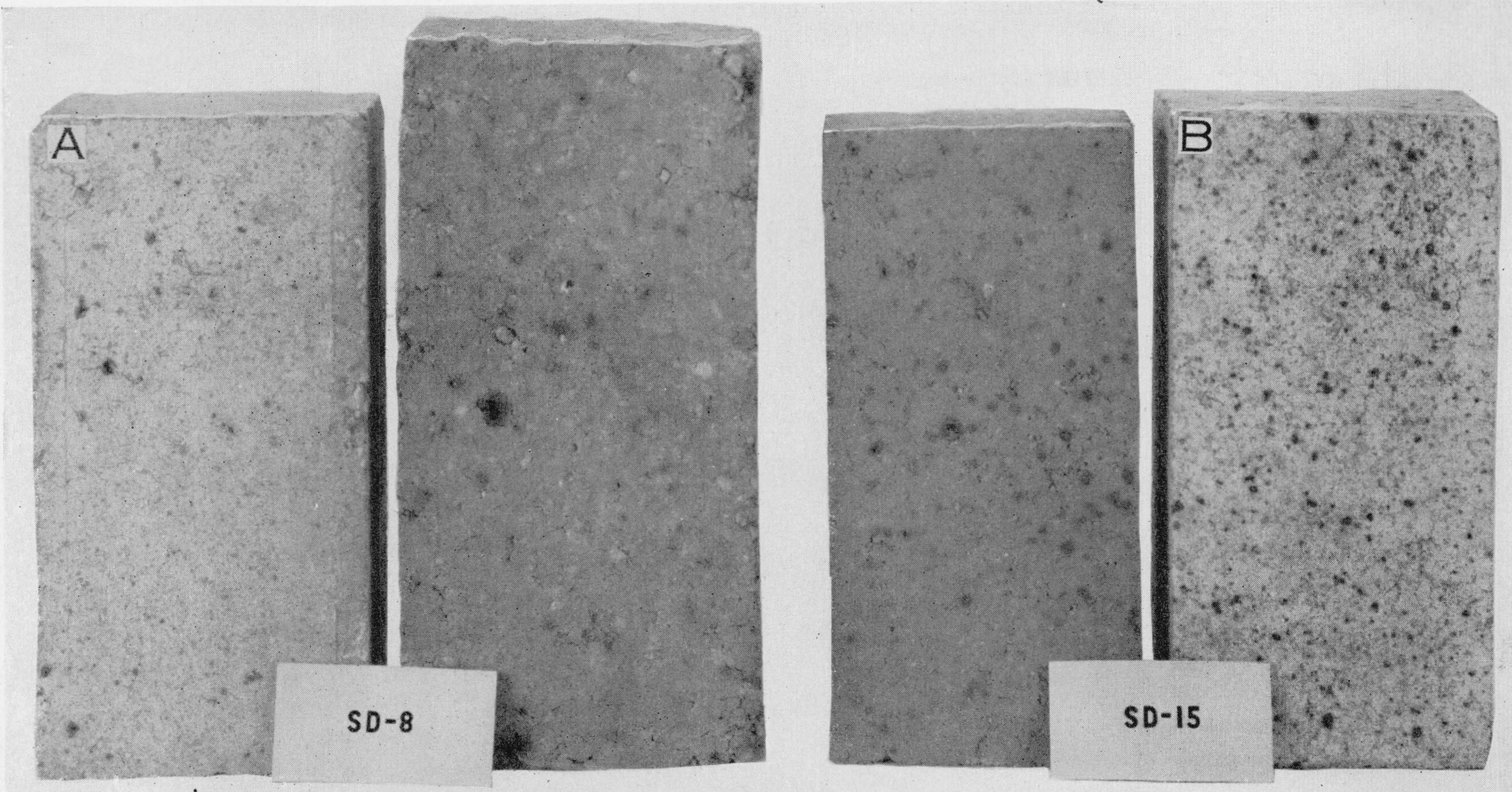

Figure 10.-Extremes in expansion and contraction due to reheating at $1,600^{\circ} C$ for 5 hours. Brand SD-8 expanded 30 percent, and brand SD-15 contracted 6.7 percent. Specimens $A$ and $B$ were not reheated. 

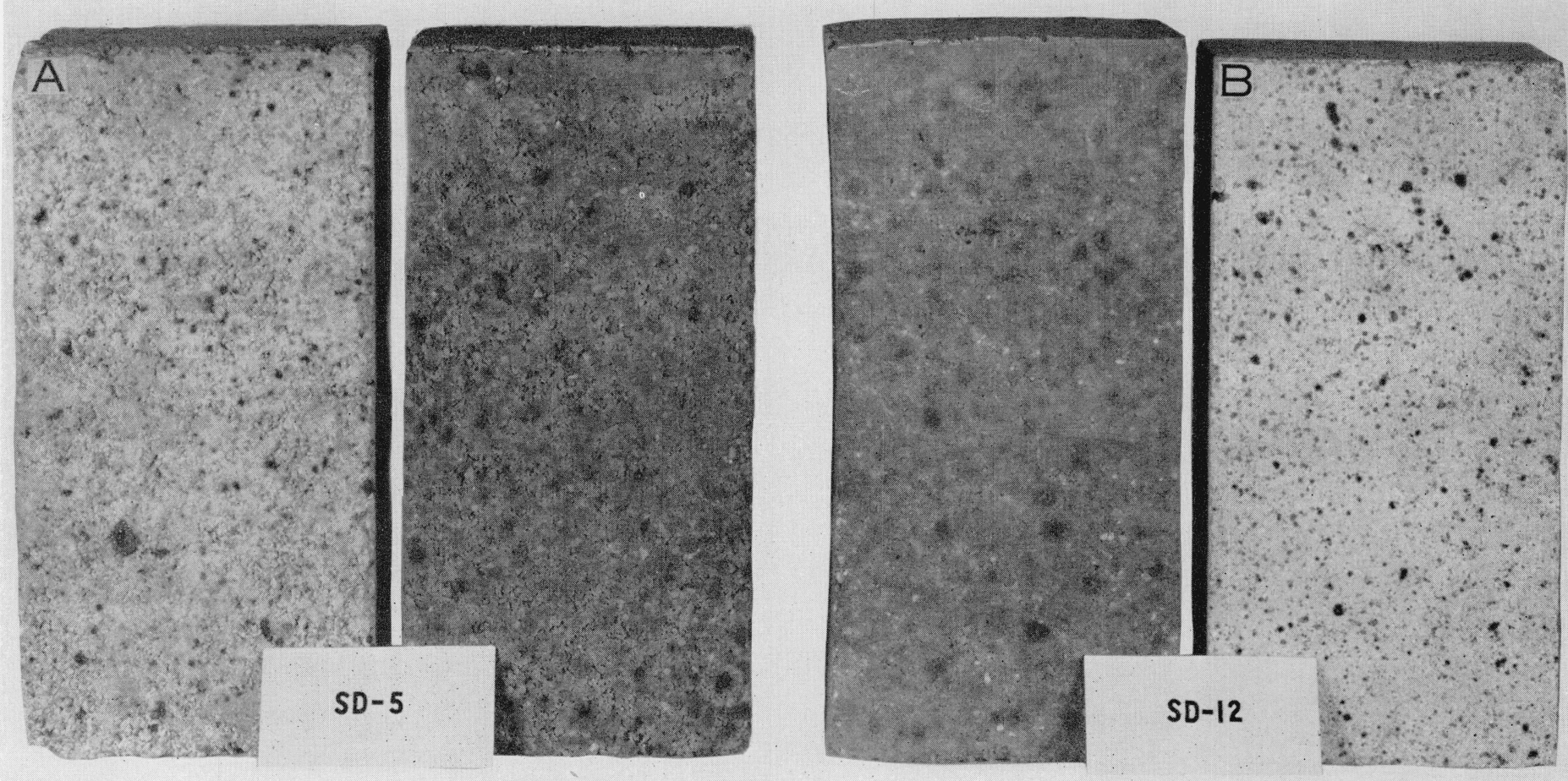

Figure 11.-Brands $S D-5$ and $S D-12$ before and after the reheating at $1,600^{\circ} C$ for 5 hours.

The former was outstanding because of constancy of volume, the latter because of distortion as indicated by the constricted central portion of the specimen. Specimens $A$ and $B$ were not reheated. 
TABLE 2. Linear and volume changes and absorption of fire-clay bricks of the super duty class, reheated at $1,600^{\circ} \mathrm{C}$ for 5 hours, and their bulk densities and pyrometric cone equivalents

[Values represent average of 3 specimens, column 3 excepted]

\begin{tabular}{|c|c|c|c|c|c|c|c|c|c|c|c|c|c|c|c|c|}
\hline \multirow{4}{*}{ Brand } & \multirow{4}{*}{ Received } & \multirow{4}{*}{$\begin{array}{l}\text { Pyro- } \\
\text { metric } \\
\text { cone } \\
\text { equiv- } \\
\text { alent }\end{array}$} & \multirow{4}{*}{$\begin{array}{l}\text { Bulk } \\
\text { den- } \\
\text { sity }\end{array}$} & \multicolumn{4}{|c|}{ Absorption } & \multirow{2}{*}{\multicolumn{3}{|c|}{$\begin{array}{l}\text { Linear change } 1 \text { based on } \\
\text { measurements with extenso- } \\
\text { meter after reheating at } 1,600^{\circ} \\
\mathrm{C} \text { for } 5 \text { hours at furnace } \\
\text { pressure } 2 \text { of- }\end{array}$}} & \multicolumn{6}{|c|}{$\begin{array}{l}\text { Volume change } 1 \text { after reheating at } 1,600^{\circ} \text { for } 5 \text { hours at } \\
\text { furnace pressure }{ }^{2} \text { of:- }\end{array}$} \\
\hline & & & & \multirow{3}{*}{$\begin{array}{l}\text { As } \\
\text { received }\end{array}$} & \multicolumn{3}{|c|}{$\begin{array}{l}\text { After reheating at } 1,600^{\circ} \mathrm{C} \\
\text { for } 5 \text { hours at furnace } \\
\text { pressure } 2 \text { of:- }\end{array}$} & & & & 0.05 & 5 in. & 0.4 & in. & 0.6 & in. \\
\hline & & & & & \multirow[b]{2}{*}{0.05 in. } & \multirow[b]{2}{*}{0.4 in. } & \multirow[b]{2}{*}{$0.6 \mathrm{in.}$} & \multirow[b]{2}{*}{0.05 in. } & \multirow[b]{2}{*}{$0.4 \mathrm{in.}$} & \multirow[b]{2}{*}{0.6 in. } & \multicolumn{6}{|c|}{ Based on measurements with- } \\
\hline & & & & & & & & & & & $\begin{array}{l}\text { Extenso- } \\
\text { meter }\end{array}$ & $\begin{array}{l}\text { Sand } \\
\text { volumeter }\end{array}$ & $\begin{array}{c}\text { Exten- } \\
\text { so- } \\
\text { meter }\end{array}$ & $\begin{array}{l}\text { Sand } \\
\text { volu- } \\
\text { meter }\end{array}$ & $\begin{array}{c}\text { Exten- } \\
\text { so- } \\
\text { meter }\end{array}$ & $\begin{array}{l}\text { Sand } \\
\text { volu- } \\
\text { meter }\end{array}$ \\
\hline 1 & 2 & 3 & 4 & 5 & 6 & 7 & 8 & 9 & 10 & 11 & 12 & 13 & 14 & 15 & 16 & 17 \\
\hline SD-1.. & Mar. 1941 & $\begin{array}{l}\text { Cone } \\
33-34\end{array}$ & $\begin{array}{l}l b / f t^{3} \\
143.7\end{array}$ & \multirow{3}{*}{$\begin{array}{r}\text { Percent } \\
7.1 \\
4.5 \\
5.5 \\
7.7 \\
8.1\end{array}$} & \multirow{3}{*}{$\begin{array}{r}\text { Percent } \\
4.4 \\
2.5 \\
4.9 \\
4.0 \\
3.6\end{array}$} & $\begin{array}{r}\text { Percent } \\
5.2\end{array}$ & $\begin{array}{r}\text { Percent } \\
5.1\end{array}$ & \multirow{3}{*}{$\begin{array}{r}\text { Percent } \\
0.8 \\
3+7 \\
+2.1 \\
0.9 \\
.7\end{array}$} & $\begin{array}{l}\text { Per- } \\
\text { cent } \\
0.7\end{array}$ & $\begin{array}{l}\text { Per- } \\
\text { cent } \\
0.6\end{array}$ & \multirow{3}{*}{$\begin{array}{r}\text { Percent } \\
2.5 \\
2.9 \\
+6.7 \\
3.2 \\
4.4\end{array}$} & \multirow{3}{*}{$\begin{array}{r}\text { Percent } \\
2.0 \\
2.5 \\
+5.8 \\
+5.7 \\
3.3 \\
4.3\end{array}$} & $\begin{array}{l}\text { Per- } \\
\text { cent } \\
2.3\end{array}$ & $\begin{array}{l}\text { Per- } \\
\text { cent } \\
2.5\end{array}$ & $\begin{array}{l}\text { Per- } \\
\text { cent } \\
2.0\end{array}$ & $\begin{array}{l}\text { Per- } \\
\text { cent } \\
\quad 3.0\end{array}$ \\
\hline SD-2. & $\left\{\begin{array}{l}\text { Nov. } 1940 \\
\text { Dec. } 1940\end{array}\right.$ & 33 & 147.5 & & & 5.4 & & & +2.3 & & & & +7.7 & +6.0 & & \\
\hline $\begin{array}{l}\text { SD }-3 \ldots \\
\text { SD }-4 \ldots\end{array}$ & $\begin{array}{l}\text { Nov. } 1940 \\
\text { Apr. } 1941\end{array}$ & $\begin{array}{l}34 \\
33\end{array}$ & $\begin{array}{l}140.7 \\
137.4\end{array}$ & & & $\begin{array}{l}4.0 \\
4.1\end{array}$ & 4.1 & & $\begin{array}{r}0.7 \\
.5\end{array}$ & .8 & & & $\begin{array}{l}2.6 \\
4.2\end{array}$ & $\begin{array}{l}2.8 \\
4.7\end{array}$ & 3.5 & 36 \\
\hline SD-5... & $\ldots$............ & 33 & 139.7 & $5.9\left(\begin{array}{lll}4 & 7.5\end{array}\right)$ & 4.9 & (4 5.2) & & +.2 & +.1 & & 0.6 & 1.4 & 0.8 & 0.7 & & \\
\hline SD-6s & F Feb. 1941 & 33 & 144.5 & 6.3 & 3.1 & 1.1 & & +.6 & & & +1.5 & +1.1 & & & & \\
\hline & $\begin{array}{l}\text { Oct. } 1943 \\
\text { SNov. } 1940\end{array}$ & $\begin{array}{l}33 \\
33\end{array}$ & 137.9 & 7.2 & $\begin{array}{l}1.2 \\
3.1\end{array}$ & & & $.2(4.4)$ & .1 & & $0.8(41.4)$ & $1.8\left(\begin{array}{ll}4 & 1.2\end{array}\right)$ & 1.2 & .9 & & \\
\hline SD-7 & A Apr. 1942 & & & 7.1 & 2.3 & 2.6 & & $\begin{array}{l}+5 \\
+.5\end{array}$ & +.4 & & $\begin{array}{c}0.0 \\
3+.9\end{array}$ & $\begin{array}{r}0.7 \\
0.7\end{array}$ & +1.0 & +.6 & & \\
\hline SD-8... & May 1942 & 33 & 143.0 & 6.2 & 10.7 & 9.8 & & +10.0 & +8.2 & & +27.2 & $3+30.0$ & +28.2 & +27.8 & & \\
\hline $\mathrm{SD}-9^{3} \ldots$ & $\left\{\begin{array}{l}\text { Nov. } 1940 \\
\text { Feb. } 1942\end{array}\right.$ & 33 & $\begin{array}{l}145.4 \\
143.9\end{array}$ & $\begin{array}{l}6.1 \\
6.1\end{array}$ & $\begin{array}{l}2.5 \\
3.2\end{array}$ & 3.5 & & 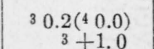 & & & 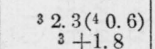 & $31.7\left(\begin{array}{r}4 \\
3+1.5\end{array}\right.$ & +26 & & & \\
\hline SD-10 & Dec. 1940 & 33 & 129.8 & 8.2 & 12.8 & 12.4 & 11.9 & $\begin{array}{r}1.0 \\
+4.5\end{array}$ & $\begin{array}{l}1.1 \\
+4.6\end{array}$ & +4.1 & $\begin{array}{r}1.8 \\
+14.4\end{array}$ & $\begin{array}{r}+1.0 \\
+13.6\end{array}$ & $\begin{array}{r}2.0 \\
+14.7\end{array}$ & $\begin{array}{r}+14.7 \\
+14.7\end{array}$ & +12.8 & +13.7 \\
\hline $\begin{array}{l}\text { SD-11.... } \\
\text { SD-12 }\end{array}$ & Dec. 1941 & $\begin{array}{l}33 \\
33\end{array}$ & 152. 2 & 4.8 & 1.3 & 1.8 & 2.3 & $0(4+0.4)$ & $\begin{array}{r}0.2 \\
6+4.4\end{array}$ & $\begin{array}{r}0.0 \\
+2.9\end{array}$ & $+0.5\left({ }^{4}+1.3\right)$ & $+1.1(4+1.0)$ & $\begin{array}{r}0.6 \\
6\end{array}$ & $\begin{array}{r}0.4 \\
0+128\end{array}$ & 0.7 & +0.2 \\
\hline & . & & 127.8 & 9.7 & & 9.0 & 9.4 & +5 & $0+4.4$ & +2.9 & +10.3 & +14.2 & $0+13.2$ & $0+12.8$ & +7.7 & +8.0 \\
\hline $\mathrm{SD}-13^{5}$ & $\begin{cases}\text { Oct. } & 1940 \\
\text { Aug. } & 1942\end{cases}$ & 33 & $\begin{array}{l}147.1 \\
144.5\end{array}$ & $\begin{array}{l}4.9 \\
5.4\end{array}$ & $\begin{array}{l}1.4 \\
2.3\end{array}$ & - & $\ldots$ & 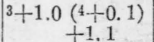 & & & 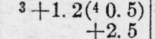 & $3+0.8\left({ }^{4} 1.1\right)$ & & & & -... \\
\hline $\mathrm{SD}-14^{j}$ & Nov. 1940 & 33 & 142. 2 & 6.4 & 1.5 & 3.1 & & 1.2 & & & 3.9 & 4.5 & & & & \\
\hline SD-15 & $\begin{array}{l}\text { Uct. } 1943 \\
\text { Feb. } 1941\end{array}$ & 33 & 133.9 & 9.8 & 4.3 & 4. 9 & 4.6 & 1.6 & $\begin{array}{l}1.1 \\
1.6\end{array}$ & 2.1 & 6.1 & 6.7 & $\begin{array}{l}3.5 \\
5.2\end{array}$ & $\begin{array}{l}4.0 \\
5.3\end{array}$ & 6.4 & 6.5 \\
\hline SD-16.. & Sept. 1943 & $34-35$ & 129.0 & 11. 3 & & 8.4 & & & 0.7 & & & & & & & \\
\hline
\end{tabular}


or expansion at the ends of the brick. In a case like this the change of volume determination based on linear measurements is apt to be misleading. For SD-5, the brick expanded slightly in the long dimension, but actually the volume decreased slightly. This is caused by shrinkage in either or both the $4 \frac{1}{2}-$ or $2 \frac{1}{2}$-inch dimensions. Here also the volume change as determined with the volumeter, will give a more complete picture of what actually occurred. In general the volume changes determined by either method were in agreement, except in cases where the specimens had become distorted.

\section{(c) ABSORPTION}

The water absorptions of the super duty class of firebricks as received from the manufacturer ranged from 4.5 to 11.3 percent (table 2 , column 5). For all but three brands, reheating at $1,600^{\circ} \mathrm{C}$ for 5 hours caused the absorption to decrease. For brands SD-8, SD-10, and SD-12, the three that had high increases in permanent volume, the absorption had increased after the reheating at $1,600^{\circ} \mathrm{C}$ with the maximum obtained when the furnace pressure was maintained at 0.05 inch of water. For the other brands, change in furnace pressure apparently had little effect on the absorption.

\section{(d) PYROMETRIC CONE EQUIVALENT}

The pyrometric cone equivalents of the super duty class of bricks as received are given in table 2 , column 3 . No value of less than 33 was obtained and for three brands, SD-1, SD-3, and SD-16, the pce was above 33 .

\section{(e) BULK DENSITY}

The bulk densities of all brands of the super duty class of bricks as received are given in table 2 , column 4 . They range from a low of $127.7 \mathrm{lb} / \mathrm{ft}^{3}$ for brand SD-12 to a high of $152.2 \mathrm{lb} / \mathrm{ft}^{3}$ for brand SD-11.

\section{TESTS OF THE HIGH HEAT DUTY CLASS OF FIRE-CLAY BRICK}

\section{(a) SPALLING}

The results of the spalling tests of firebricks submitted as of high heat quality are presented in table 3 . For five brands, samples were received on two different dates as indicated in column 2 . The losses sustained when the specimens were tested as stretchers are given in column 4 and as headers in column 5 . The pressure maintained in the furnace during preheating of the brick was 0.4 inch of water.

The loss for the brick in all stretcher construction ranged from 0.1 percent for brand $\mathrm{HH}-10$ to 20.9 percent for brand $\mathrm{HH}-24$, and for those in all header construction from 1.2 percent for brands $\mathrm{HH}-8$ and $\mathrm{HH}-10$ to 25.9 percent for brand $\mathrm{HH}-25$. In 16 tests made of 25 brands the loss sustained was far greater for brick in header than in stretcher construction. For nine brands the spalling loss in header construction was not significantly different from that in stretcher construction. Figure 12 shows preheated brands $\mathrm{HH}-3$ and $\mathrm{HH}-8$ for both types of construction. Brand $\mathrm{HH}-3$ showed considerable pitting, probably caused by fusion of iron compounds and bloating of the heated face of the brick. Figure 13 shows the same bricks after the spalled pieces had been removed, that is, after the test had been 

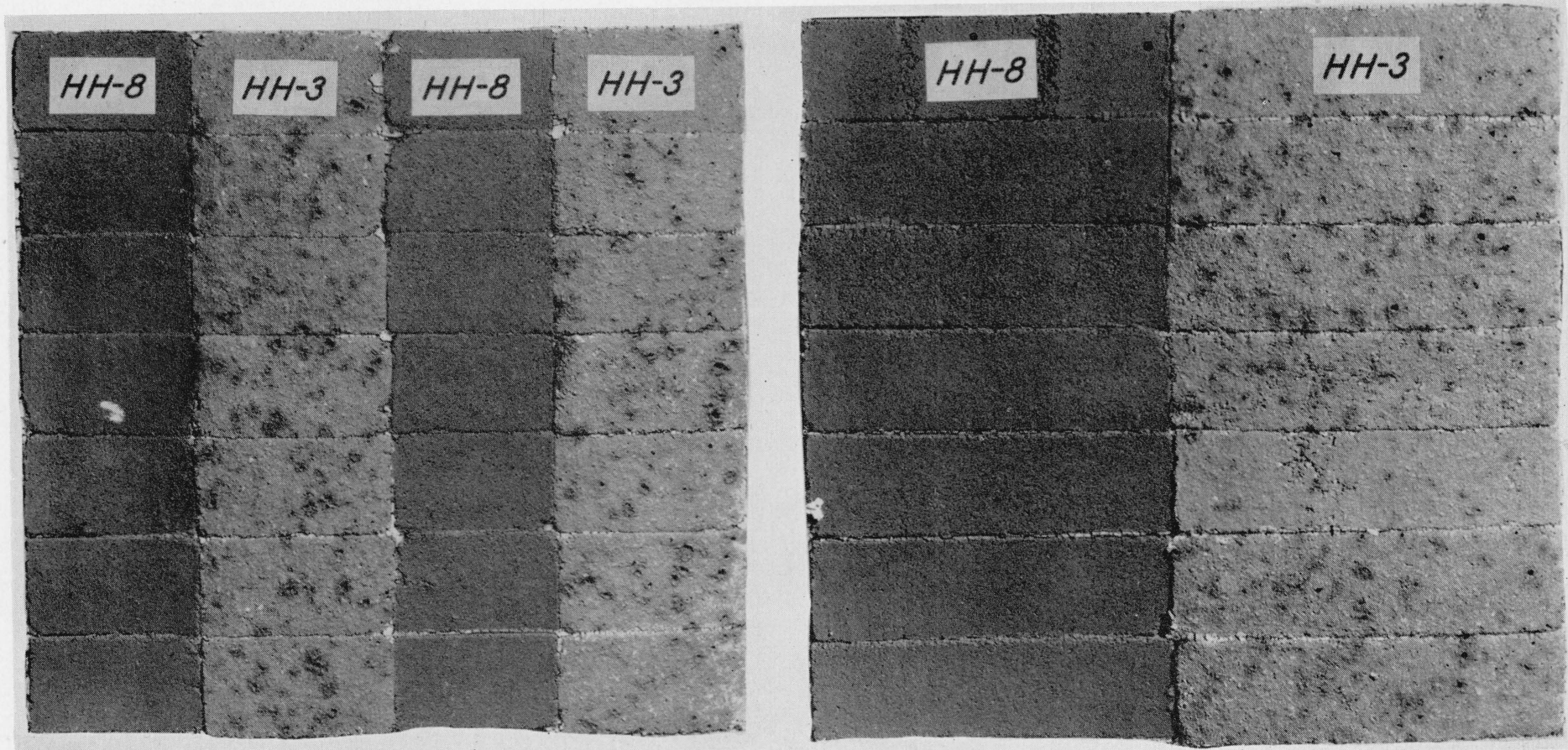

Figure 12.- Panels of high heat duty brands $H H-3$ and $H H-8$.

Panels illustrate all header and all stretcher construction after the preheating treatment at $1,600^{\circ} \mathrm{C}$ for 24 hours. Brand HH-3 shows considerable pitting and expansion or bloating on the front face. 

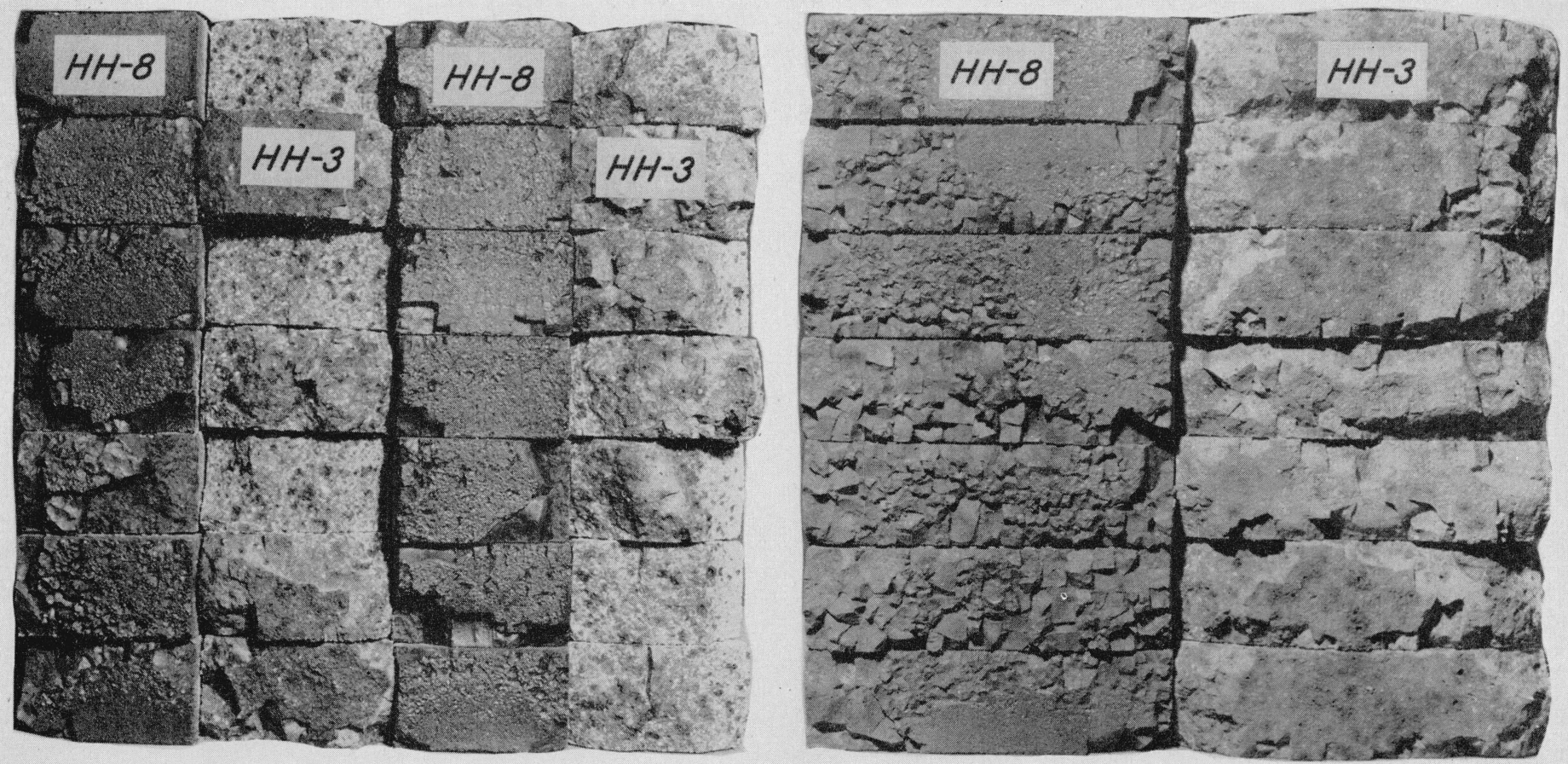

FigURE 13.-Brands $H H-3$ and $H H-8$ ajier completion of the spalling test.

The former sustained a loss of over 100 percent more in header construction than in stretcher, whereas the loss for the latter was about the same for either type of construction. 
TABLE 3.-Spalling losses of high heat duty fire-clay bricks in panel ${ }^{1}$ tests

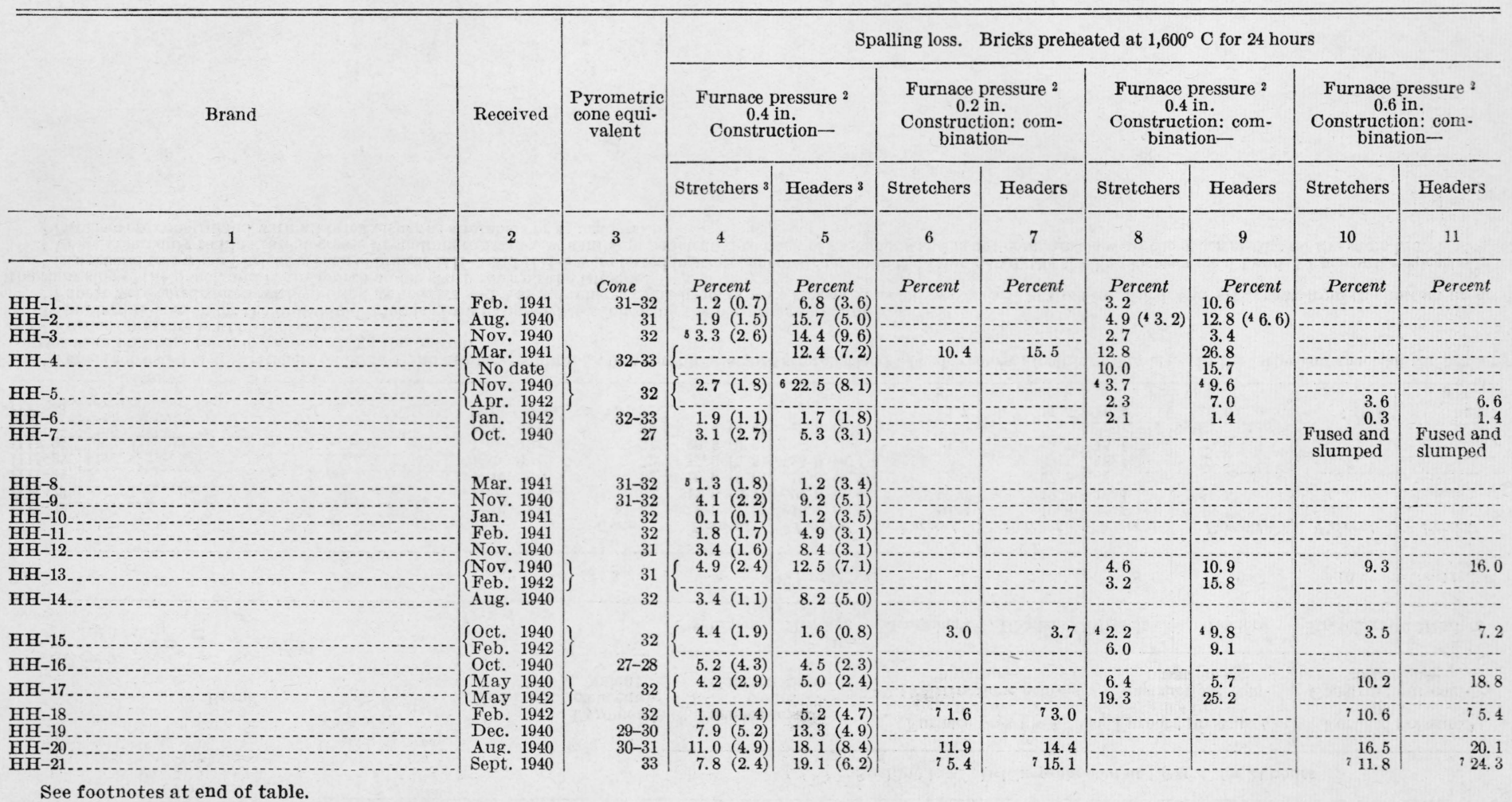


TABLE 3.-Spalling losses of high heat duty fire-clay bricks in panel ${ }^{1}$ tests-Continued

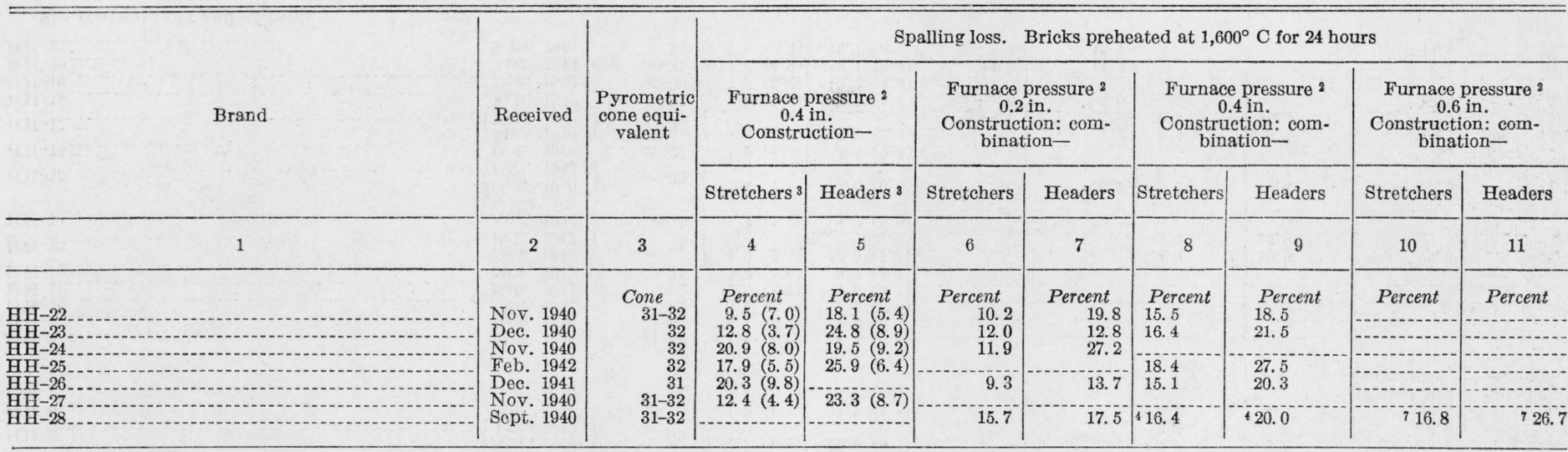

1 Panels consisted of all stretchers (column 4), all headers (column 5), or a combination of 5 stretcher and 2 header courses (columns 6 to 11 ). In the latter construction the header courses were numbers 1 and 6 , counting from the bottom.

2 Furnace pressure is in inch of water.

3 Standard deviation for the individual brick is given in parentheses following the percentage spalling loss.

4 Panels were constructed with 10 brick as headers and 9 as stretchers. The headers were staggered as follows: 2 each in the first, third, and sixth rows from the bottom up on

the right side of the panel, and in the fourth and seventh rows on the left side.

In a second test when 7 bricks of each of brands HH- 3 and HH- 8 were tested in stretcher construction in the same panel, the spalling losses were 6.1 and 3.7 percent, respectively.

Value given only to illustrate decrease in spalling resistance when flame penetrated to back of specimens and is not comparable with the other results on the same brand.

Panels were constructed with all brick either as stretchers or as headers. 

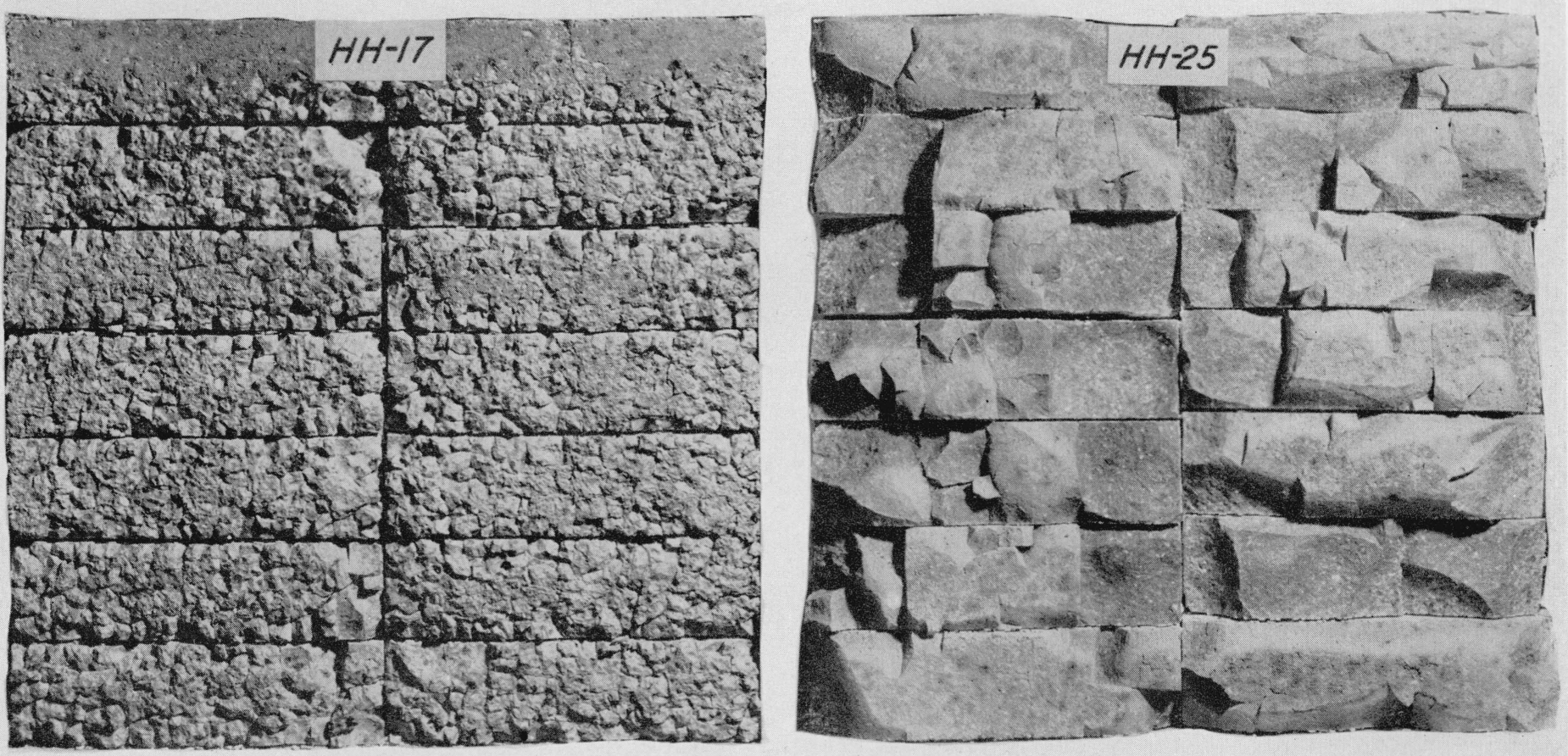

Figure 14. - The two general types of spalling encountered in the high heat duty class of firebrick laid as stretchers. Brand $\mathrm{HH}-17$ spalled in small angular pieces which dropped off during the heating and cooling cycles. Specimens of brand HH-25 appeared to be intact until the specimens were removed and scraped, at which time large conchoidal spalls dropped away. 

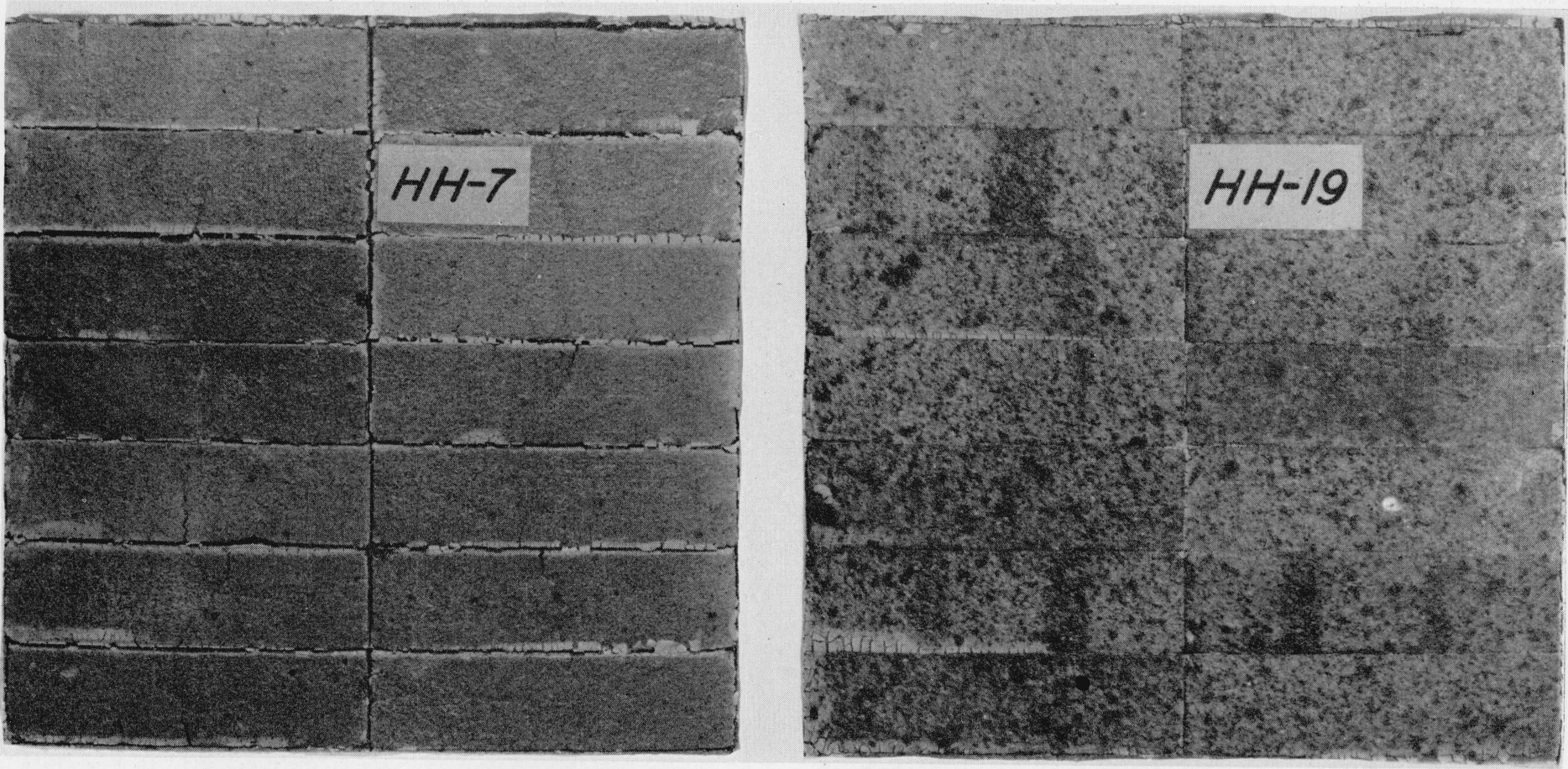

FIGURE 15.-Two brands of the highly siliceous type of fire-clay brick after the 24-hour preheating at $1,600^{\circ} \mathrm{C}$. Brand $\mathrm{HH}-7$ contracted, whereas brand $\mathrm{HH}-19$ had considerable expansion. 
completed. Brand HH-8 was one of the group that sustained approximately the same percentage loss in header construction as in stretcher. Brand $\mathrm{HH}-3$ was one in which the loss was far greater in header than in stretcher construction, namely 14.4 and 3.3 percent, respectively.

The 14.4 percent spalling loss of brand $\mathrm{HH}-3$ in header construction was not duplicated in the test where the construction was a combination (column 9) of brick laid as headers and stretchers. In the first test the losses for the individual specimens for some unaccountable reason were highly erratic ranging from 1.7 to 29.7 percent. Also, the loss of 22.5 percent (column 5) noted for brand $\mathrm{HH}-5$ was not duplicated in a later test (column 9). This may be accounted for by the fact that, due to shrinkage of the specimens, the flame penetrated to the back face of the brick, the thermo-couple at this location registering $1,425^{\circ} \mathrm{C}$. The ideal condition of having the brick remain compact in the panel even though shrinkage of the specimens occurred did not often develop.

Brand $\mathrm{HH}-21$ was of interest in that there was a tendency for this brick to shrink in the middle portion and expand or bulge at the kiln markings near the ends. The brick tested in stretcher construction showed low resistance to spalling, particularly over the kiln-marked areas.

Figure 14 illustrates the two general types of spalling, which occurred when specimens were laid in the panel as stretchers. For brand $\mathrm{HH}-17$ the spalled pieces dropped off during the heating and cooling cycles, whereas for brand $\mathrm{HH}-25$, the tested brick appeared to be intact until the panel was dismantled.

Brands HH-6 and HH-18 represent the same manufacturer's product, the former differing from the latter only in that it was deaired during the pressing operation. The absorption of the deaired brick was 9.4 percent (average of 5 specimens) and that of the non-deaired 10.4 percent. In panels of stretcher construction, the spalling was about the same (1.9 versus 1.0 -percent loss), but in header construction they showed some divergence, the deaired brick having lost 1.7 percent and the non-deaired 5.2 percent.

The spalling losses for the bricks laid in the panels in the combination of stretchers and headers are given in table 3 , columns 6 to 11 .

The highly siliceous type of firebricks are represented in table 3 by brands $\mathrm{HH}-7$ and $\mathrm{HH}-19$. These two brands are shown in figure 15 in stretcher construction after having been preheated. In the panel, brand HH-7 showed considerable shrinkage, whereas brand $\mathrm{HH}-19$ showed considerable expansion. The pyrometric cone equivalent of the former was 27 and that of the latter 29-30, which may partially account for the different phenomena. Figure 16, $A$, shows these brands in panels of header construction after completion of the tests. Brand HH-19 lost 13.3 percent, whereas brand HH-7 lost only 5.3 percent, which was not expected because of its lower pyrometric cone equivalent. Most of the spalled pieces fell off the former during the progress of the test, whereas brand HH-7 lost nothing until the specimens were removed from the panel.

The results in columns 4 and 8 agree within 3 percent for 10 and between 3 and 6 percent for the other 3 of 13 tests made of 12 brands of bricks from the same shipments tested as stretchers in both constructions, with the pressure maintained in the furnace during the 24- 
hour preheating period at $0.4 \pm 0.05$ inch of water. For different shipments the results agree within 3 percent for the three brands, which are comparable. The results in columns 5 and 9 for brick from the same shipment tested as headers in both constructions agree within 3 percent for 8 of 12 brands tested; for different shipments the results are within 3 percent in 2 of 3 comparable tests.

Figure 17 shows the relation between the spalling losses, obtained before and after scraping with the mason's trowel, for the high heat duty bricks tested in stretcher construction. A similar relation exists for the other classes of bricks, as well as for all three classes in header construction. Hence it would be possible to set specification limits on spalling in terms of loss of the unscraped specimens (or gravity), which would be as satisfactory as the present lim $\mathrm{mts}$ in terms of loss after scraping, thereby eliminating the personal factor.

(1) Effect of furnace pressure on spalling of firebrick-Table 3 gives results for 10 brands of bricks after having been preheated at two

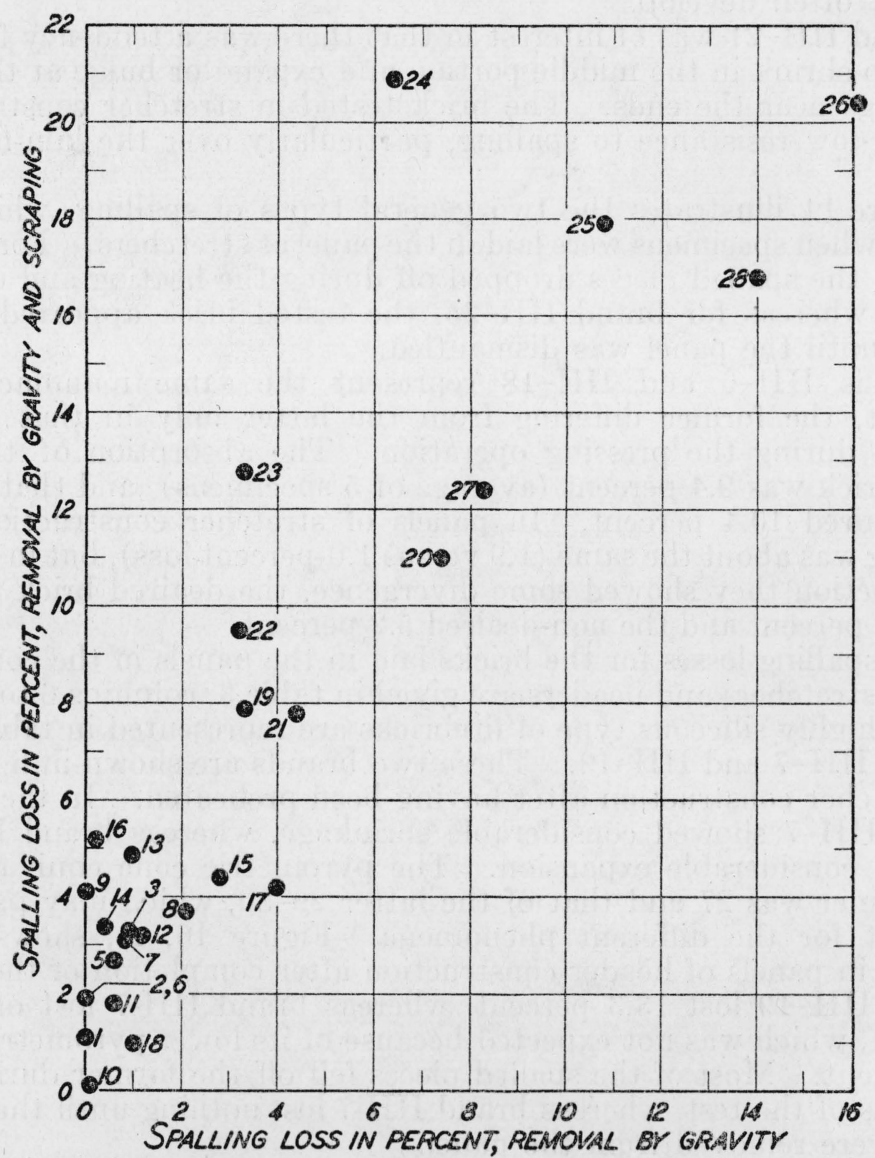

FIGURE 17.-Relation between spalling losses by gravity only and those by a combination of gravity and scraping to remove adhering kaolin bedding.

The plotted points represent results obtained with the high heat duty brands of bricks in panels of all stretcher construction. 

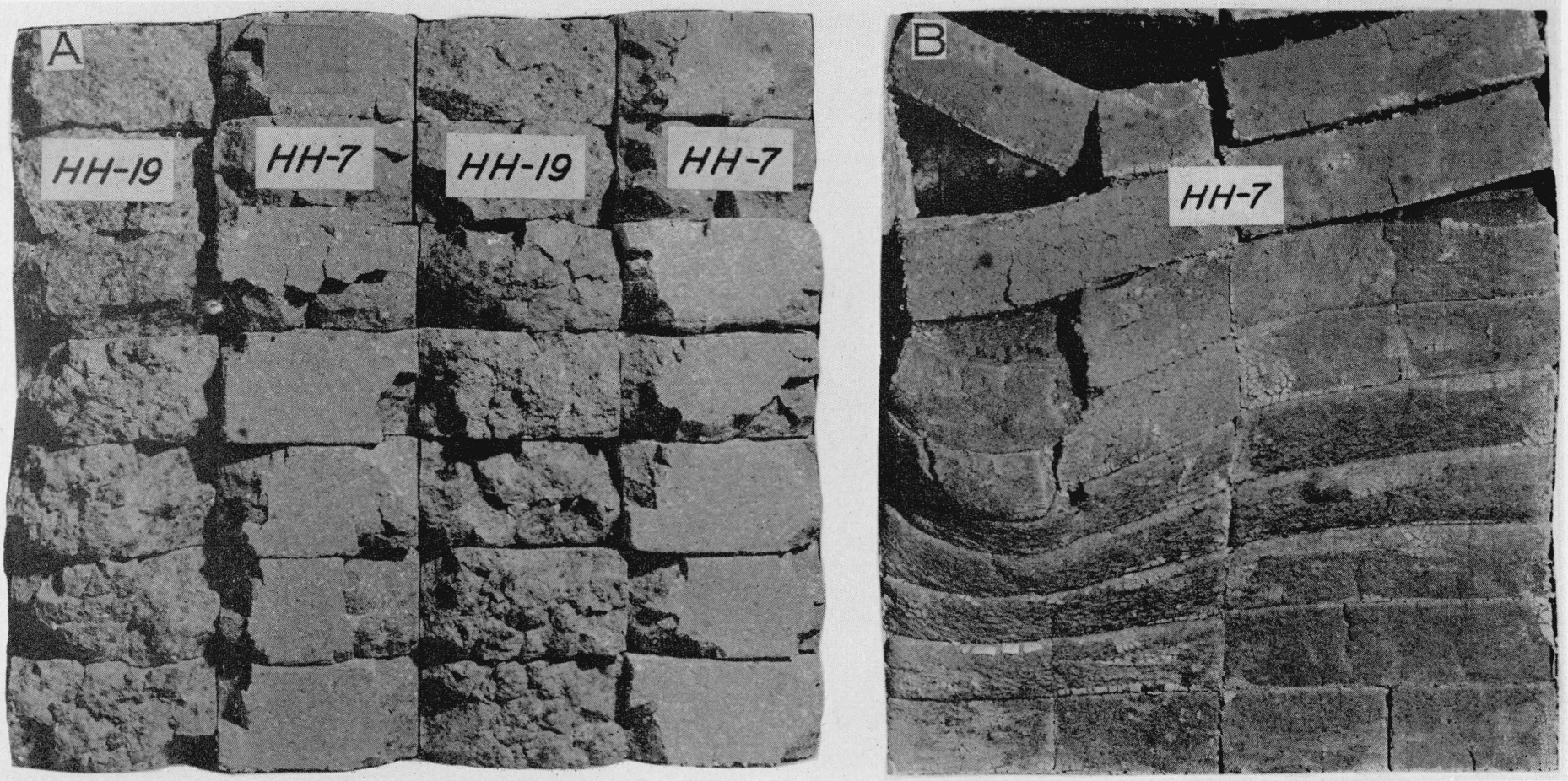

FIGURE 16-A Highly siliceous firebricks brands $\mathrm{HH}-7$ and $\mathrm{HH}-19$ after having been tested for spalling in header construction. The spalling loss of the former was 5.3 percent and of the latter 13.3 percent. For brand $\mathrm{HH}-19$ the spalls dropped while the test was in progress. $B$, Brand $\mathrm{HH}-7$ after preheating for 24 hours at $1,600^{\circ} \mathrm{C}$ with a pressure in the furnace of 0.6 inch of water instead of 0.4 inch. 

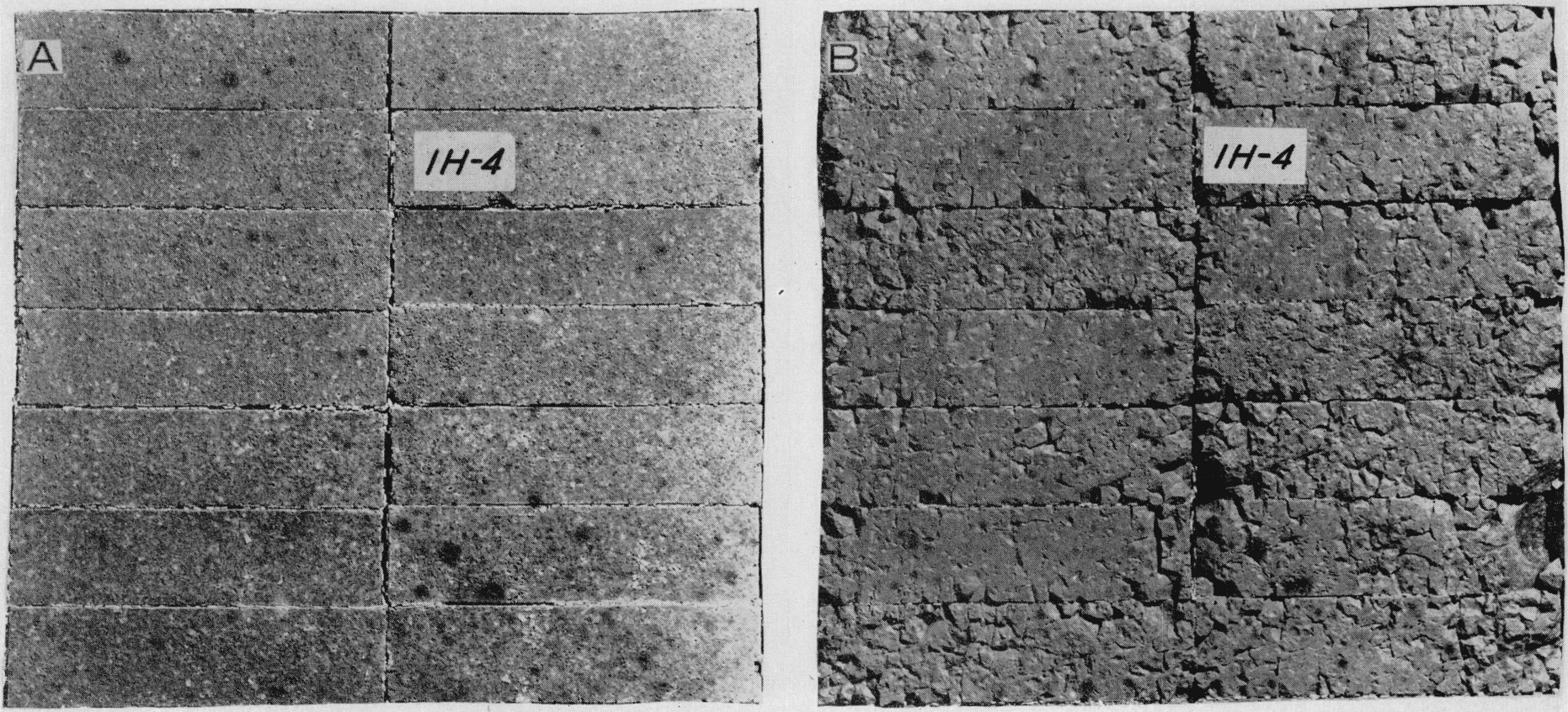

Figure 18.-Brand $I H-4, A$, after the preheating at $1,600^{\circ} \mathrm{C} ; \mathrm{B}$, after the spalling test. After having been preheated, the specimens had no visible cracks, but after the spalling test they appeared badly shattered. Structure was excellent, however, for the spalling loss
was only 3.1 percent. 
different furnace pressures and for five brands after having been preheated at three different furnace pressures. Although there are exceptions, as for example $\mathrm{HH}-6$ and $\mathrm{HH}-15$, the spalling losses of the bricks tended to increase with increase in the pressure maintained in the furnace during preheating. Brand HH-6 (deaired) is outstanding in that, irrespective of the furnace pressure, the spalling loss in each case was negligible. Figure $16, B$, shows brand HH-7 after having been preheated at a pressure of 0.6 inch of water in the furnace. Apparently the effect produced by the high furnace pressure was more than a brick having a pyrometric cone equivalent of 27 could withstand.

The middle graph in figure 8 illustrates the tendency for the spalling to increase with the higher furnace pressure during preheating of seven brands of high heat duty brick, stretcher construction only.

(2) Uniformity of specimens-The standard deviations of the spalling losses by the individual brick in all stretcher as well as those in all header construction reported in table 3 , columns 4 and 5 , give an indication of the uniformity of the firebricks in the samples.

\section{(b) PYROMETRIC CONE EQUIVALENT}

The pyrometric cone equivalents of the high heat duty brands of firebrick are given in table 3 , column 3 . Fourteen of the 28 brands failed to comply with the pce requirement of 32 specified for the high heat duty class of firebrick in Federal Specification HH-B-671b.

\section{(c) LINEAR, VOLUME, AND ABSORPTION CHANGES CAUSED BY REHEATING}

In table 4 are given the linear, volume, and absorption changes of 10 brands of high heat duty bricks caused by reheating at $1,400^{\circ} \mathrm{C}$ for 5 hours. Neither the linear nor the volume changes were large enough to be significant. Three of the brands, namely, HH-7, HH-17, and HH-26, were specially selected for testing because they showed

TABLE 4.--Linear ${ }^{1}$ and volume ${ }^{1}$ changes and absorption ${ }^{1}$ of fire-clay bricks of the high heat duty class

\begin{tabular}{|c|c|c|c|c|}
\hline \multirow[b]{2}{*}{ Brand } & $\begin{array}{l}\text { Linear }{ }^{2} \\
\text { change }\end{array}$ & $\begin{array}{l}\text { Volume } 23 \\
\text { change }\end{array}$ & \multicolumn{2}{|c|}{ Absorption } \\
\hline & \multicolumn{2}{|c|}{$\begin{array}{l}\text { Due to heating at } \\
1,400^{\circ} \mathrm{C} \text { for } 5 \text { hours }\end{array}$} & As received & $\begin{array}{l}\text { After heating } \\
\text { samples at } \\
1,400^{\circ} \mathrm{C} \text { for } \\
5 \text { hours }\end{array}$ \\
\hline $\begin{array}{l}\mathrm{HH}-4 \\
\mathrm{HH}-6{ }^{4} \\
\mathrm{HH}-7 \\
\mathrm{HH}-8\end{array}$ & $\begin{array}{r}\text { Percent } \\
+2.1 \\
0.1 \\
.2 \\
.5 \\
.6\end{array}$ & $\begin{array}{r}\text { Percent } \\
+3.3 \\
0.2 \\
+.4 \\
1.1 \\
2.2\end{array}$ & $\begin{array}{r}\text { Percent } \\
8.3 \\
9.4 \\
15.8 \\
7.3 \\
8.9\end{array}$ & $\begin{array}{r}\text { Percent } \\
8.0 \\
7.4 \\
15.0 \\
6.4 \\
7.4\end{array}$ \\
\hline 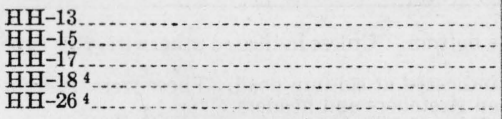 & $\begin{array}{r}+.2 \\
.3 \\
.5 \\
.6 \\
0\end{array}$ & $\begin{array}{l}0.7 \\
.9 \\
1.6 \\
1.7 \\
0.1\end{array}$ & $\begin{array}{r}7.4 \\
8.2 \\
10.4 \\
10.6 \\
15.0\end{array}$ & $\begin{array}{r}5.8 \\
6.2 \\
9.5 \\
7.5 \\
14.2\end{array}$ \\
\hline
\end{tabular}

1 Average of 3 specimens.

2 Values indicate shrinkage, however, when preceded by a plus sign indicate expansion.

3 Determined with the sand volumeter.

4 Bricks heated with a pressure in the furnace of about 0.4 inch of water; for all others the pressure was 0.2 inch. 
decided shrinkages after the $1,600^{\circ} \mathrm{C}$ preheating in the panel furnace. It therefore may be concluded that the specified reheating temperature of $1,400^{\circ} \mathrm{C}$ is too low to have any value in predicting linear or volume changes of brick suitable for service in high heat duty installations.

The absorption was somewhat affected, as indicated by reductions ranging up to 3.1 percent (brand $\mathrm{HH}-18$ ).

\section{PANEL SPALLING TEST OF THE INTERMEDIATE HEAT DUTY CLASS OF FIRE-CLAY BRICK}

Table 5 gives the results of the spalling tests of the six brands of firebrick submitted as of intermediate heat quality. In columns 4 and 5 are the results of tests of bricks preheated at $1,500^{\circ} \mathrm{C}$ in panels of the combination header and stretcher construction. The spalling loss was low in all cases except for brand IH-6.

The spalling losses of three of these brands preheated at $1,600^{\circ} \mathrm{C}$ are given in columns 7 and 8 . The effect on spalling of the preheating at the higher temperature is well illustrated by brand IH-5. Preheating the specimens at $1,500^{\circ} \mathrm{C}$ induced no loss in the spalling test. In contrast, after the preheating at $1,600^{\circ} \mathrm{C}$ the losses ranged from 9.7 to 27.8 percent in a series of five tests covering different combinations of panel construction and pressure in the furnace.

TABLE 5.-Spalling losses of intermediate heat duty fire-clay bricks in panel tests and the effect on spalling of preheating at $1,500^{\circ} \mathrm{C}$ versus $1,600^{\circ} \mathrm{C}$ on some brands of intermediate and high heat duty bricks

\begin{tabular}{|c|c|c|c|c|c|c|c|c|}
\hline \multirow[t]{2}{*}{ Brand } & \multirow[t]{2}{*}{ Received } & \multirow[t]{2}{*}{$\begin{array}{l}\text { Pyromet- } \\
\text { ric cone } \\
\text { equiv- } \\
\text { alent }\end{array}$} & \multicolumn{2}{|c|}{$\begin{array}{c}\text { Spalling loss. Bricks } \\
\text { preheated } 1 \text { at } \\
1,500^{\circ} \text { C for } 24 \\
\text { hours } \\
\text { Construction: }{ }^{2} \text { Com. } \\
\text { bination- }\end{array}$} & \multirow[t]{2}{*}{$\begin{array}{l}\text { Tempera- } \\
\text { ture of } \\
\text { back face } \\
\text { of brick } \\
\text { panel }\end{array}$} & \multicolumn{2}{|c|}{$\begin{array}{l}\text { Spalling loss. Bricks pre- } \\
\text { heated at } 11,600^{\circ} \mathrm{C} \text { for } \\
24 \text { hours } \\
\text { Construction: } 2 \text { Stretchers } \\
\text { or headers alone or in } \\
\text { combination- }\end{array}$} & \multirow[t]{2}{*}{$\begin{array}{l}\text { Temperature } \\
\text { of back face } \\
\text { of brick panel }\end{array}$} \\
\hline & & & Stretchers & Headers & & Stretchers & Headers & \\
\hline 1 & 2 & 3 & 4 & 5 & 6 & 7 & 8 & 9 \\
\hline LH. & June 1942 & $\begin{array}{c}\text { Cone } \\
31-32\end{array}$ & Percent & Percent & ${ }^{\circ} C_{130}$ & Percent & Percent & ${ }^{\circ} \mathrm{C}$ \\
\hline IIH & July 1942 & $31-32$ & $\begin{array}{r}.0 \\
.3\end{array}$ & 1.5 & 1,145 & & & \\
\hline IH & Apr. 1941 & 32 & .4 & 1.8 & 1,065 & & & \\
\hline IH & .....do do & 32 & .0 & & 1,155 & 3.1 & 34.6 & $71,200,81,165$ \\
\hline IH-5.. & Nov. 1940 & 31 & .0 & .0 & 1,080 & $\left\{\begin{array}{r}21.8(019.0) \\
39.7 \\
2613.2\end{array}\right.$ & $\begin{array}{r}318.7 \\
2614.8\end{array}$ & $\begin{array}{r}71,180,81,220 \\
1,195\end{array}$ \\
\hline $\mathrm{IH}-6 \ldots$ & June 1942 & $29-30$ & 19.0 & 29.2 & 1,130 & $\begin{array}{r}322.1 \\
28 \\
2622.7\end{array}$ & $\begin{array}{r}321.0 \\
2628.2\end{array}$ & $\begin{array}{r}71,160 \\
1,130\end{array}$ \\
\hline $\mathrm{HH}-9$. & Nov. 1940 & $31-32$ & 3.5 & 10.4 & 1,220 & 34.1 & 39.2 & ${ }^{8} 1,165$ \\
\hline $\mathrm{HH}-13$ & .... do & 31 & 0.8 & 0.4 & 1,120 & 4. 6 & 10.8 & 1,210 \\
\hline 배-17 ... & May 1942 & 32 & .0 & .0 & 1,180 & 19. 3 & 25.2 & 1,430 \\
\hline 뵤-21... & Sept. 1940 & 33 & 3.2 & 7.9 & 1,145 & $\begin{array}{l}37.8 \\
35.4\end{array}$ & 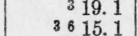 & $\begin{array}{r}71,170,81,195 \\
781,160\end{array}$ \\
\hline НВ $-25 \ldots$ & Feb. 1942 & 32 & 5.2 & 9.1 & 1,080 & 18.4 & 27.7 & 1,195 \\
\hline НH $-28 \ldots$ & Sept. 1940 & $31-32$ & 15.0 & 23.2 & 1,105 & $\begin{array}{r}416.4 \\
2615.7\end{array}$ & $\begin{array}{r}420.0 \\
2617.5\end{array}$ & $\begin{array}{l}1,155 \\
1.105\end{array}$ \\
\hline
\end{tabular}

1 Furnace pressure was 0.4 inch of water, except as noted.

2 Header courses were numbers 1 and 6 , counting from the bottom. Unless indicated otherwise, this type of construction was used.

${ }_{3}$ Panels constructed with only the type of construction indicated at column head. These were used for comparison since no panels were constructed of combination stretchers and headers.

4 Panel constructed with 10 brick as headers and 9 as stretchers. The headers were staggered as follows: 2 each in the first, third, and sixth rows from bottom up on the right side of the panel, and the fourth and seventh rows on the left side.

5 Duplicate test except panels constructed as described in footnote 2

6 Bricks tested with furnace pressure of 0.2 inch of water.

7 Temperature observation on panel having all brick laid as stretchers.

8 Temperature observation on panel having all brick laid as headers.

- This temperature applies to panel which contained the brick having spalling losses indicated in parentheses. 
An interesting example of brick structure is illustrated by brand IH-4. It was furnished as intermediate heat quality, but was tested for spalling resistance after having been preheated at $1,500^{\circ} \mathrm{C}$ and at $1,600^{\circ}$ C. No surface cracks were visible either before or after the specimens were preheated (fig. 18, A). An examination of the tested brick (fig. 18, B) could easily lead to the conclusion that a large portion of the specimens would drop off when scraped with the trowel to remove the adhering kaolin. The structure of the brick was such, however, that after cleaning, the loss was but 3.1 percent.

Table 5 also presents results of certain tests of six brands of brick submitted as of high heat quality. These had been tested for spalling resistance after having been preheated at $1,600^{\circ} \mathrm{C}$, but for the following reasons were also tested after having been preheated at $1,500^{\circ} \mathrm{C}$. Brands HH-9, HH-13, and HH-28 were so tested because the pce was below the 32 specified in the Federal Specification for this class of brick. Only brand $\mathrm{HH}-13$ showed a significant decrease in spalling loss when subjected to the lower preheating temperature. Figure 19 shows specimens of brand $\mathrm{HH}-28$ after completion of the spalling tests; those on the left had been preheated at $1,600^{\circ} \mathrm{C}$ and those on the right at $1,500^{\circ} \mathrm{C}$. The structure of this brand of brick apparently was such that it could not resist destruction even though the prehea ting temperature was reduced 100 degrees. Brands $\mathrm{HH}-17, \mathrm{HH}-21$, and $\mathrm{HH}-25$ were tested after having been preheated at $1,500^{\circ} \mathrm{C}$ because of the high spalling losses (header only in case of $\mathrm{HH}-25$ ) resulting when preheated at $1,600^{\circ} \mathrm{C}$. Brand $\mathrm{HH}-17$ had no loss when the preheating was at $1,500^{\circ} \mathrm{C}$, whereas losses of 19.3 to 25.2 percent occurred on stretchers and headers, respectively, when the preheating was at $1,600^{\circ} \mathrm{C}$. The other two brands had much smaller losses when preheated at the lower temperature. The higher temperature caused considerable shrinkage of brand $\mathrm{HH}-17$, which in turn caused the joints to separate and the flame to penetrate to the back face of the brick. The temperature of $1,430^{\circ} \mathrm{C}$ noted on the back of the panel was from 200 to 300 degrees higher than it would have been if the brick had not shrunk. A similar condition was noted for brand $\mathrm{IH}-5$ in which case a temperature of $1,450^{\circ} \mathrm{C}$ was recorded for the back of the panel.

The maximum temperatures obtained on the back of the brick panels preheated at $1,500^{\circ} \mathrm{C}$ for 24 hours are given in table 5 , column 6 . The values range from $1,065^{\circ}$ to $1,220^{\circ} \mathrm{C}$, and the average is about $1,130^{\circ} \mathrm{C}$. These compare with a range of $1,105^{\circ}$ to $1,220^{\circ} \mathrm{C}$ and an average of about $1,175^{\circ} \mathrm{C}$ (not including the two values above $1,400^{\circ}$ C) for the back of the panels preheated at $1,600^{\circ} \mathrm{C}$ for 24 hours. An average of only the observations made on panels preheated at a furnace pressure of 0.4 inch of water, is about $1,185^{\circ} \mathrm{C}$.

The relation of furnace pressure to spalling resistance is illustrated in figure $8, I H$, for two brands of the intermediate heat duty firebrick, based on data obtained on brick preheated at $1,600^{\circ} \mathrm{C}$. In general, it may be concluded from figure 8 that the higher the furnace pressure during preheating the greater the spalling loss.

The pyrometric cone equivalents for the intermediate heat duty bricks are given in table 5 . Brand IH-6 failed to meet the pce requirement of 31 specified for this class in the Federal Specifications for Fireclay-Brick. 


\section{COMPARISON OF HEADER AND 41/2-INCH STRETCHER CONSTRUCTION}

Table 6 gives results on resistance to spalling in seven tests of four brands of high heat duty firebrick when laid as standard 9-inch stretchers and also as $4 \frac{112}{2}$-inch stretchers. For comparative purposes, the losses sustained when these bricks were tested as headers are also tabulated. There was no significant difference in resistance to spalling regardless of the three ways deaired brand $\mathrm{HH}-6$ was laid; the loss was low in all tests. For brand $\mathrm{HH}-18$ (identical with $\mathrm{HH}-6$ but not deaired), the spalling losses for the cut stretcher specimens were greater in the three tests made at different furnace pressures than either the full stretcher or header specimens. Although the differences in test results were small when a furnace pressure of 0.2 inch of water was used, such was not the case for pressures of 0.4 and 0.6 inch. The $4 \frac{1}{2}$-inch stretcher had by far the greater loss, as is illustrated in figure 20 , (left) by brand $\mathrm{HH}-18$. One-half of the panel consisted of 14 halfstretcher ( $D$ and adjacent column) specimens and for comparative purposes, the other half contained 14 header specimens ( $A$ and adjacent column). In the other three tests, two on brand HH-21 and one on $\mathrm{HH}-25$, the losses on the $4 \frac{1}{2}$-inch stretchers and the headers were about the same.

\section{COMPARISON OF BONDED HEADER AND UNBONDED HEADER CONSTRUCTION}

Table 6 also gives the results of spalling tests of five brands of firebrick, the panels for which were built from specimens consisting of two header bricks bonded with an air-setting refractory mortar. Figure 20, right, shows a panel built of bricks treated in that manner,

TABLE 6.-Spalling losses of high heat duty firebricks in panels constructed of headers with or without mortar, ${ }^{1} 9$-inch or $41 / 2$-inch stretchers ${ }^{2}$

\begin{tabular}{|c|c|c|c|c|c|c|}
\hline \multirow{2}{*}{ Brand } & \multirow{2}{*}{$\begin{array}{c}\text { Pressure in } \\
\text { furnace } \\
\text { during } \\
\text { the pre- } \\
\text { heating }\end{array}$} & Spalling loss. & \multicolumn{4}{|c|}{$\begin{array}{l}\text { Bricks preheated at } 1,600^{\circ} \mathrm{C} \text { for } 24 \text { hours. } \\
\text { Panel construction:- }\end{array}$} \\
\hline & & $\begin{array}{l}\text { 9-inch } \\
\text { stretcher }\end{array}$ & $\begin{array}{l}41 / 2 \text {-inch } \\
\text { stretcher }\end{array}$ & $\begin{array}{c}\text { Header }{ }^{3} \\
\text { (no mortar) }\end{array}$ & $\begin{array}{l}\text { Header } \\
\text { (with } \\
\text { mortar) }\end{array}$ & $\begin{array}{l}\text { Header } \\
\text { (bond } \\
\text { broken) }\end{array}$ \\
\hline 1 & 2 & 3 & 4 & 5 & 6 & 7 \\
\hline $\begin{array}{l}\mathrm{HH}-2 \ldots \ldots \\
\mathrm{HH}-5 \\
\mathrm{HH}-7\end{array}$ & $\begin{array}{l}\text { Inches } \\
\text { of water } \\
0.4 \\
.4 \\
.4 \\
.4\end{array}$ & $\begin{array}{r}\text { Percent } \\
1.9 \\
2.7 \\
1.9 \\
3.1\end{array}$ & $\begin{array}{r}\text { Percent } \\
0.4 \\
0.4\end{array}$ & $\begin{array}{r}\text { Percent } \\
15.7 \\
9.6 \\
1.7 \\
5.3\end{array}$ & $\begin{array}{r}\text { Percent } \\
4.9 \\
3.9 \\
0.6\end{array}$ & $\begin{array}{r}\text { Percent } \\
12.5 \\
11.6 \\
2.3\end{array}$ \\
\hline $\begin{array}{l}\text { НH } 18 \\
\text { НH}-18 \\
\text { НH } \mathrm{H}-18 \\
\text { Н }-21\end{array}$ & $\begin{array}{l}.2 \\
.4 \\
.6 \\
.2\end{array}$ & $\begin{array}{r}1.6 \\
1.0 \\
10.6 \\
5.4\end{array}$ & $\begin{array}{r}4.5 \\
20.6 \\
16.5 \\
18.7\end{array}$ & $\begin{array}{r}3.0 \\
5.2 \\
5.4 \\
15.1\end{array}$ & $\mid \begin{array}{ll}2 \\
-\ldots \ldots\end{array}$ & (n) \\
\hline 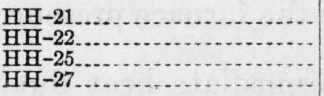 & $\begin{array}{l}.4 \\
.4 \\
.4 \\
.4\end{array}$ & $\begin{array}{r}7.8 \\
9.5 \\
17.9 \\
12.4\end{array}$ & $\begin{array}{r}20.5 \\
24.0 \\
-2.0\end{array}$ & $\begin{array}{l}19.1 \\
18.1 \\
25.9 \\
23.3\end{array}$ & 7.1 & $\begin{array}{r}21.9 \\
19.4\end{array}$ \\
\hline
\end{tabular}

1 An air-setting mortar was used to bond 2 headers into the equivalent of a 9 -inch standard-size brick and all specimens were laid in the kaolin bed as specified.

2 These were standard 9-inch straights cut in 2 equal parts parallel to the $2 \frac{1}{2}$ - by $41 / 2$-inch dimension.

3 Taken from table 3 . Values are for panels of all stretcher or all header construction if available.

1 The mortar-bonded specimen was separated at the joint and the spalled sections removed. Values for brands $\mathrm{HH}-2$ and $\mathrm{HH}-27$ are the average of 14 specimens; those for $\mathrm{HH}-5$, HH-7, and $\mathrm{HH}-22$ the average of 8 specimens. 

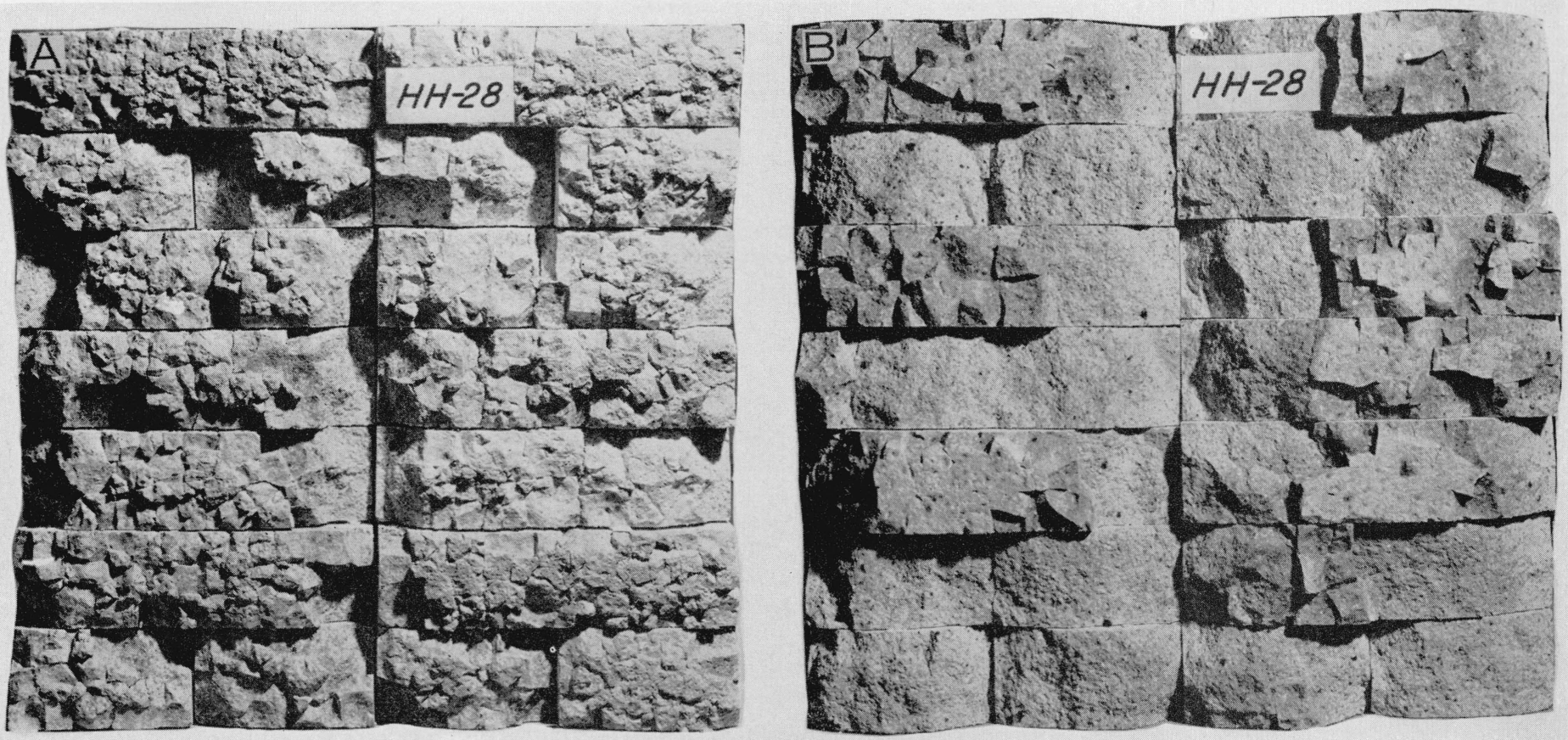

FiguRE 19.-Two panels of brand HH-28 after completion of the spalling tests.

The spalling loss was high, namely about 15 percent, regardless of whether the panel had been preheated at $1,600^{\circ} \mathrm{C}, A$; or at $1,500^{\circ} \mathrm{C}, B$. 


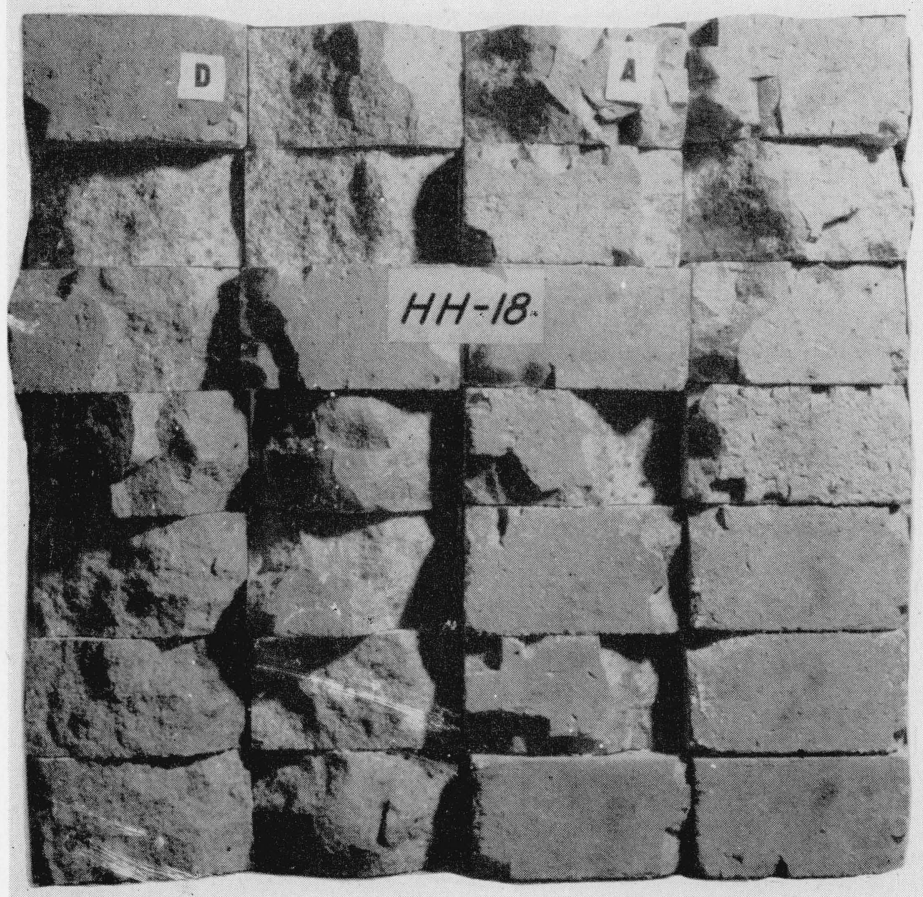

FIG. 20 (left). - A comparison of spalling resistance of brand $H H-18$ laid as $4^{1} / 2$-inch stretchers, columns 1 and 2 ; and as headers, columns 3 and 4 .

The stretchers had much lower resistance to spalling than headers.

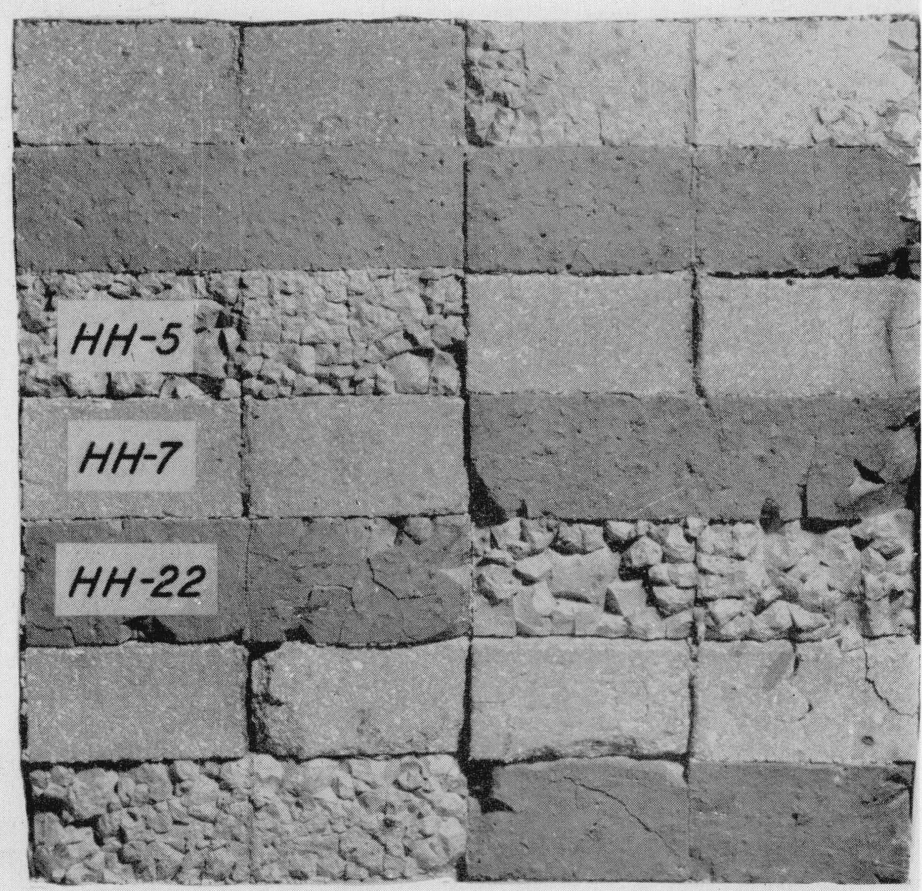

FIG. 20 (right).-Header specimens of brands $H H_{-5}, H H_{-7}$, and HH-22 after spalling test.

Specimens had been bonded with an air-setting refractory mortar before the preheating. The several specimens of each brand may be identified by referring to those labeled. 
after completion of the spalling test but before the spalled pieces had been removed. This panel contained three brands of bricks, namely, $\mathrm{HH}-5, \mathrm{HH}-7$, and $\mathrm{HH}-22$. The results in table 6 , columns 5 to 7 , indicate that these brands, as also $\mathrm{HH}-2$, have quite a high resistance to spalling when only the specimens bonded with the air-setting mortar are considered. When, however, the specimen was separated at the bonded joint and again scraped with the trowel to remove the adhering kaolin, the results were quite different. For all brands the losses agree quite well on the header brick without mortar and on those which had been bonded but the bond broken.

Heindl and Mong ${ }^{18}$ reported the extensibilities in tension of five of the same brands included in this paper, but of an earlier date of manufacture. A comparison of the resistance of brick of any one brand in header and stretcher constructions and the extensibilities crosswise (header) and lengthwise (stretcher) indicates that there was a marked tendency for the spalling loss to increase with a decrease in the extensibility of the brick in the direction parallel to the face exposed in the panel test and a corresponding tendency for loss for headers to be greater than for stretchers when the extensibility crosswise was less than lengthwise.

In general, from the limited number of tests made, it may be concluded that there was a tendency for the spalling loss to increase as the number of joints in the brick panel increased. However, the tendency for the loss for headers to be greater than for stretchers may have resulted in part from the differences in extensibility in the two directions of the brick.

\section{SUMMARY AND CONCLUSIONS}

Sixteen brands of fire-clay brick of the super duty class, 28 of the high heat, and 6 of the intermediate heat duty classes supplied by 19 manufacturers were tested primarily for resistance to spalling by the panel test method of the American Society for Testing Materials. Variations of this method included tests of panels of specimens in all header construction and also panels of combinations of stretcher and header construction. The gas pressures in the furnace were controlled to nominal $0.2,0.4$, and 0.6 inch of water.

For the super duty bricks, preheated at $1,650^{\circ} \mathrm{C}$ with the furnace gas pressure maintained at 0.4 inch of water, 12 of the 14 brands tested in all stretcher construction, and 9 of the 14 tested in all header construction had losses of less than 4 percent.

For the high heat duty bricks, preheated at $1,600^{\circ} \mathrm{C}$ with the furnace pressure maintained at 0.4 inch, 16 of the 26 brands tested in all stretcher construction had spalling losses of less than 5 percent, but 18 of the 26 tested in all header construction had losses of more than 5 percent.

For the intermediate heat duty bricks preheated at $1,500^{\circ} \mathrm{C}$, the spalling losses were low for five of the six brands tested.

Although there were exceptions, spalling losses increased for a majority of brands with increase in the gas pressure maintained in the furnace during the preheating.

\footnotetext{
${ }_{18}$ R. A. Heindl and L. E. Mong, Young's modulus of elasticity, strength, and extensibility of refractories in tension, J. Research NBS 17, 463 (1936) RP923.

Brands $3,7,8,11$, and 16 in the earlier publication are the same as high heat duty brands $4,21,28,15$, and 7 , respectively, in this report.
}

$623634-45-7$ 
In the first of two general types of spalling, large pieces of the specimens spalled conchoidally, but remained in position until the brick were removed from the panel or scraped with a trowel. In the second type the spalled pieces were small and angular and frequently dropped spontaneously during the heating and cooling cycles.

A relation of possible value was noted between the spalling loss of the tested specimen as removed from the panel and the total loss after scraping with a trowel to remove adhering kaolin. On the basis of that relation it would be possible to set specification limits on spalling in terms of loss of the unscraped specimen, which would be as satisfactory as the present terms of loss by scraping, and the personal factor would be largely eliminated.

For the super duty class of bricks, 11 of the 16 brands tested had expanded after having been reheated at $1,600^{\circ} \mathrm{C}$ for 5 hours, but in only three cases were the linear expansions greater than 2.5 percent. Results of tests on volume changes were more dependable than those on linear changes because of distortions, which may occur in the specimens during reheating. In exceptional cases only was there a tendency for the firebrick to have decreased linear and volume changes with increase in the furnace pressure from 0.05 to 0.6 inch of water.

The absorptions of the super-duty class of fire brick as received ranged from 4.5 to 11.3 percent, the bulk densities from 129 to 152.2 $\mathrm{lb} / \mathrm{ft}^{3}$, and the pyrometric cone equivalents were 33 or above. Reheating at $1,600^{\circ} \mathrm{C}$ for 5 hours caused the absorption to decrease for all brands except the three that had great increases in volume. Furnace pressure had no significant effect on the absorption.

For the 10 brands of high heat duty brick tested, there was little change caused by reheating at $1,400^{\circ} \mathrm{C}$ for 5 hours in either volume or in absorption. Since three of these brands had marked shrinkage in panels preheated at $1,600^{\circ} \mathrm{C}$, it may be concluded that the reheating at $1,400^{\circ} \mathrm{C}$ is of little consequence. The absorptions for the specimens as received ranged from 7.3 to 15.8 percent.

When specimens of the high-heat duty bricks were tested as $41 / 2$-inch stretchers, the spalling loss tended to be greater than when tested either as headers or as 9-inch stretchers. When two headers were bonded with an air-setting mortar and tested as a 9-inch specimen, the spalling loss approached that of the 9-inch stretcher, but after the mortar joint was broken the loss approached that of the header. It may be concluded from the limited data that although there are exceptions, the tendency is for the test speimens to have greater spalling losses as the number of joints in the brick panel are increased. However, the tendency for the loss for headers to be greater than for stretchers may have resulted from the differences in extensibility in the two directions of the brick.

The results of this investigation make it appear desirable that consideration be given, in any proposed Federal Specification for fire-clay brick in which the panel test is specified, to limits for spalling loss based on brick laid as stretchers and as headers, a controlled atmosphere, and the gas pressure in the furance chamber during preheating.

Washıngton, September 28, 1944. 
NATIONAL BUREAU OF STANDARDS, WASHINGTON, 25 D. C.

Send me the Mathematical Tables marked $X$ below. I enclose remittance to cover the cost.

\begin{tabular}{|c|c|c|c|c|}
\hline Mark X & Title of publication & $\begin{array}{l}\text { United States and } \\
\text { its possessions, } \\
\text { and countries ex- } \\
\text { tending franking } \\
\text { privilege }\end{array}$ & Other countries & Amount enclosed \\
\hline (1. & 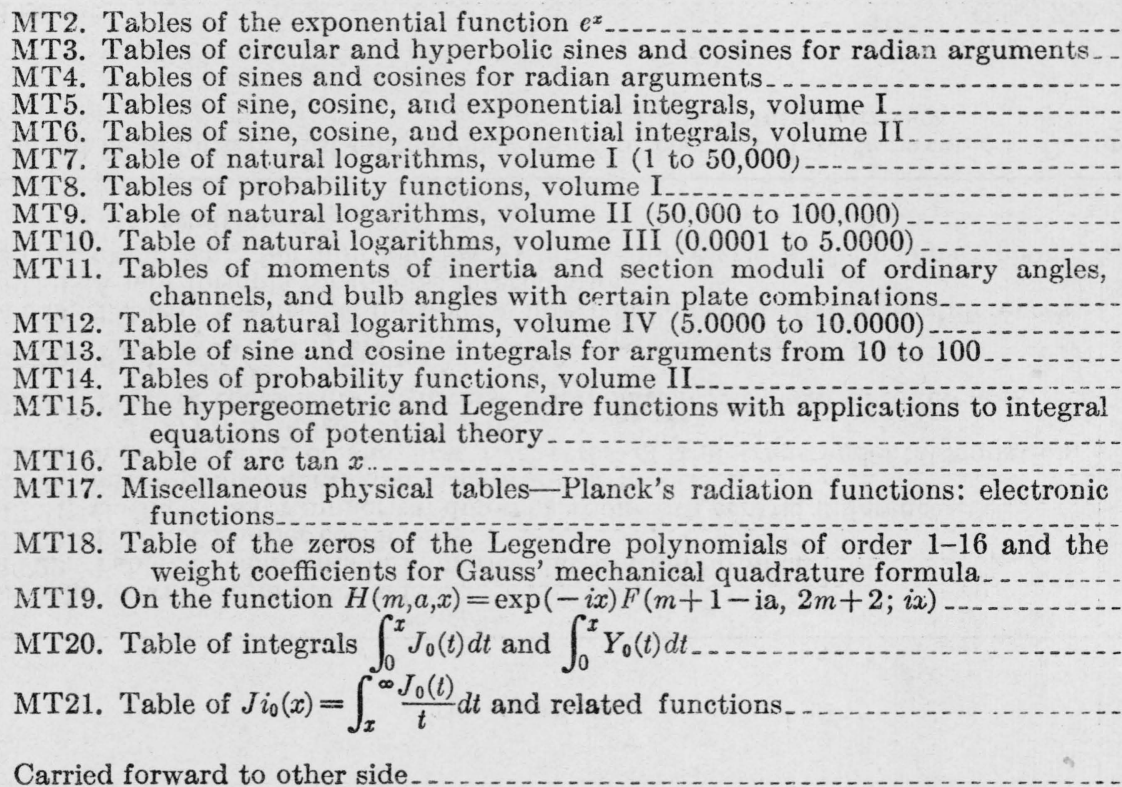 & $\begin{array}{r}\$ 2.00 \\
2.00 \\
2.00 \\
2.00 \\
2.00 \\
2.00 \\
2.00 \\
2.00 \\
2.00 \\
2.00 \\
2.00 \\
2.00 \\
2.00 \\
2.00 \\
2.00 \\
1.50 \\
.25 \\
.25 \\
.25\end{array}$ & $\begin{array}{r}\$ 2.50 \\
2.50 \\
2.50 \\
2.50 \\
2.50 \\
2.50 \\
2.50 \\
2.50 \\
2.50 \\
2.50 \\
2.50 \\
2.50 \\
2.50 \\
2.50 \\
2.50 \\
1.75 \\
.30 \\
.30 \\
.30 \\
.30\end{array}$ & \begin{tabular}{|c} 
\\
\\
\end{tabular} \\
\hline
\end{tabular}




\begin{tabular}{|c|c|c|c|c|}
\hline Mark X & Title of publication & $\begin{array}{l}\text { United States and } \\
\text { its posse esions, } \\
\text { and countries ex- } \\
\text { tending franking } \\
\text { privilege }\end{array}$ & Other countries & Amount enclosed \\
\hline (1) & $\begin{array}{l}\text { Brought forward from other side } \\
\text { MT22. Table of coefficients in numerical integration formulationtion } \\
\text { MT23. Table of Fourier coefficients } \\
\text { MT24. Coefficients for numerical differentiation with central differences } \\
\text { MT25. Seven-point Lagrangian integration formulas } \\
\text { MT26. A short table of the first five zeros of the transendental equation, } \\
\text { MT27. Table of coefficients for inverse interpolation with central differences } J_{0}(x) Y_{0}(k x)-J_{0}(k x) Y_{0}(x)=0 \\
\text { MT28. Table of } f_{n}(x)=\frac{n !}{(x / 2)} J_{n}(x) \\
\text { MT29. Table of coefficients for inverse interpolation with advancing differences } \\
\text { MT30. A new formula for inverse interpolation } \\
\text { MT31. Coefficients for interpolation within a square grid in the complex plane } \\
\text { Total remittance. }\end{array}$ & $\begin{array}{r}\$ 0.25 \\
.25 \\
.25 \\
.25 \\
.25 \\
.25 \\
.25 \\
.25 \\
.25 \\
.25\end{array}$ & $\begin{array}{r}\$ 0.30 \\
.30 \\
.30 \\
.30 \\
.30 \\
.30 \\
.30 \\
.30 \\
.30 \\
.30 \\
\end{array}$ & 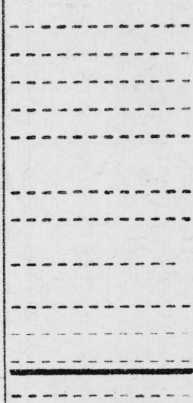 \\
\hline
\end{tabular}

Remittance should be in form of post-office money order, or check, and made payable to the order of the "National Bureau of Standards" in United States currency

Send to

Number and Street.

City, Zone, and State 


\section{MATHEMATICAL TABLES}

Attention is invited to a series of publications prepared by the Project for the Computation of Mathematical Tables conducted by the Federal Works Agency, Work Projects Administration for the City of New York, under the sponsorship of the National Bureau of Standards. The tables which have been made available through the National Bureau of Standards are listed below. A list of other WPA tables obtainable elsewhere will be sent by the Bureau on request.

There is included in this list a publication of the hypergeometric and Legendre functions (MT15), prepared by the Bureau.

MT1. Table of the First Ten Powers of the Integers From 1 to 1000: (1938) VIII+80 pages; heavy paper cover. Out of print.

MT2. Tables of the Exponential Function $e^{x}$ : The ranges and intervals of the argument and the number of decimal places in the entries are given below:

$\begin{array}{ccc}\text { Range of } x & \text { Interval of } x & \text { Decimals given } \\ -2.5000 \text { to } 1.0000 & 0.0001 & 18 \\ 1.0000 \text { to } 2.5000 & .0001 & 15 \\ 2.500 \text { to } 5.000 & .001 & 15 \\ 5.00 \text { to } 10.00 & .01 & 12\end{array}$

(1939) XV+535 pages; bound in buckram, $\$ 2.00$.

MT3. Tables of Circular and Hyperbolic Sines and Cosines for Radian Arguments: Contains 9 decimal place values of $\sin x, \cos x, \sinh x$, and $\cosh x$ for $x$ (in radians) ranging from 0 to 2 at intervals of 0.0001 . (1939) XVII +405 pages; bound in buckram, $\$ 2.00$.

MT4. Tables of Sines and Cosines for Radian Arguments: Contains 8 decimal place values of sines and cosines for radian arguments ranging from 0 to 25 at intervals of 0.001 . (1940) XXIX +275 pages; bound in buckram, $\$ 2.00$.

MT5. Tables of Sine, Cosine, And Exponential Integrals, Volume I: Values of these functions to 9 places of decimals from 0 to 2 at intervals of 0.0001 . (1940) XXVI +444 pages; bound in buckram, $\$ 2.00$.

MT6. Tables of Sine, Cosine, and Exponential Integrals, Volume II: Values of these functions to 9,10 , or 11 significant figures from 0 to 10 at intervals of 0.001 with auxiliary tables. (1940) XXXVII+225 pages; bound in buckram, $\$ 2.00$.

MT7. Table of Natural Logarithms, Volume I: Logarithms of the integers from 1 to 50,000 to 16 places of decimals. (1941) XVIII +501 pages; bound in buckram, $\$ 2.00$.

MT8. Tables of Probability Functions, Volume I: Values of these functions to 15 places of decimals from 0 to 1 at intervals of 0.0001 and from 1 to 5.6 at intervals of 0.001 . (1941) XXVIII + 302 pages; bound in buckram, $\$ 2.00$.

MT9. Table of Natural Logarithms, Volume II: Logarithms of the integers from 50,000 to 100,000 to 16 places of decimals. (1941) XVIII + 501 pages; bound in buckram, $\$ 2.00$.

MT10. Table of Natural Logarithms, Volume III: Logarithms of the decimal numbers from 0.0001 to 5.0000 , to 16 places of decimals. (1941) XVIII + 501 pages; bound in buckram, $\$ 2.00$.

MT11. Tables of the Moments of Inertia and Section Moduli of Ordinary Anglzs, Chan. nels, and Bulb Angles with Certain Plate Combinations: (1941) XIII+197 pages; bound in green cloth. $\$ 2.00$.

MT12. Table of Natural Logarithms, Volume IV: Logarithms of the decimal numbers from 5.0000 to 10.0000 , to 16 places of decimals. (1941) XXII +506 pages; bound in buckram, $\$ 2.00$.

MT13. Table of Sine and Cosine Intrgrals for Arguments from 10 to 100: (1942) XXXII+185 pages; bound in buckram, $\$ 2.00$.

MT14. Tables of Probability Functions, Volume II: Values of these functions to 15 places of decimals from 0 to 1 at intervals of 0.0001 and from 1 to 7.8 at intervals of 0.001 . (1942) XXI+344 pages; bound in buckram, $\$ 2.00$.

MT15. The Hypergeometric and Legendre Functions With Applications to Integral Eruations of Potential Theory. By Chester Snow, National Bureau of Standards. Reproduced from original handwritten manuscript. (1942) VII + 319 pages, bound in heavy paper cover. $\$ 2.00$.

MT16. TaBle of ARC TAN $x$ : Table of inverse tangents for positive values of the angle in radians. Second central differences are included for all entries. $x=[0(.001) 7(.01) 50(.1) 300(1) 2,000(10)$ 10,$000 ; 12 D \rrbracket$ (1942) XXV +169 pages; bound in buckram, $\$ 2.00$.

〔Continued on p. 4 of cover 


\section{[Continued from p. 3 of cover]}

MT17. Miscellaneous Physical Tables: Planck's Radiation Functions (Originally published in the Journal of the Optical Society of America, February 1940); and Electronic Functions. (1941) VII + 58 pages; bound in buckram, $\$ 1.50$.

MT18. Table of the Zeros of the Legendre Polynomials of Order 1-16 and the Weight Coerficients for Gauss' Mechanical Quadrature Formula. (Reprinted from Bul. Amer. Mathematical Society, October 1942.) 5 pages, with cover, 25 cents.

MT19. On the Function $H(m, a, x)=\exp (-i x) F(m+1-i a, 2 m+2 ; i x)$; with table of the confluent hypergeometric function and its filst derivative. (Reprinted from J. Math. Phys., December 1942.) 20 pages, with cover, 25 cents.

MT20. Table of Integrals $\int_{0}^{x} J_{0}(t) d t$ and $\int_{0}^{x} Y_{0}(t) d t$. (Reprinted from J. Math. Phys., May 1943.) 12 pages, with cover, 25 cents.

MT21. Table of $J i_{0}(x)=\int_{x}^{\infty} \frac{J_{0}(t)}{t} d_{t}$ and Related Functions. (Reprinted from J. Math. Phys. June 1943.) 7 pages, with cover, 25 cents.

MT22. Table of Corpicients in Numerical Intbgration Formulae. (Reprinted from J. Math. Phys., June 1943.) 2 pages, with cover, 25 cents.

MT23. Table or Fourier Cozpricients. (Reprinted from J. Math. Phys., Sept. 1943.) 11 pages, with cover, 25 cents.

MT24. Coeppicients for Numerical Differentiation With Central Diprerences. (Reprinted from J. Math. Phys., Sept. 1943.) 21 pages, with cover, 25 cents.

MT25. Seven-Point Lagrangian Intrgration Pormulas. (Reprinted from J. Math. Phys., Dec. 1943.) 4 pages, with cover, 25 cents.

MT26. A Short Table of the First Five Zeros of the Transcendental Equation. $J_{0}(x) Y_{0}(k x)-J_{0}(k x) Y_{0}(x)=0$. (Reprinted from J. Math. Phys., Dec. 1943.) 2 pages, with cover, 25 cents.

MT27. Table of Coefpicients for Inverse Interpolation with Central Diprerences. (Ree printed from J. Math. Phys., Dec. 1943.) 15 pages, with cover, 25 cents.

MT28. TABLE or $f_{n}(x)=\frac{n !}{(x / 2)^{n}} J_{n}(x)$. (Reprinted from J. Math. Phys., Feb. 1944.) 16 pages, with cover, 25 cents.

MT29. Table of Coefricients por Inverse Interpolation with Advancing Dipferences. (Reprinted from J. Math. Phys., May 1944.) 28 pages, with cover, 25 cents.

MT30. A New Formula por Inverse Interpolation. (Reprinted from Bul. Amer. Mathe matical Socizty, August 1944.) 4 pages, with cover, 25 cents.

MT31. Coepricients for Interpolation Within a Square Grid in the Complex Plane. (Reprinted from J. Math. Phys., Aug. 1944.) 11 pages, with cover, 25 cents.

Payment is required in advance. Make remittance payable to the "Nationai Bureau of Standards" and send with order, using the blank form facing page 3 of the cover.

A mailing. list is maintained for those who desire to receive announcements regarding new tables as they become available. 